\title{
Review article: the use of remotely piloted aircraft systems (RPASs) for natural hazards monitoring and management
}

\author{
Daniele Giordan $^{1}$, Yuichi Hayakawa ${ }^{2}$, Francesco $\mathrm{Nex}^{3}$, Fabio Remondino ${ }^{4}$, and Paolo Tarolli ${ }^{5}$ \\ ${ }^{1}$ Istituto di Ricerca per la Protezione Idrogeologica, Consiglio Nazionale delle Ricerche, Torino, Italy \\ ${ }^{2}$ Center for Spatial Information Science, The University of Tokyo, Tokyo, Japan \\ ${ }^{3}$ University of Twente, Faculty of Geo-Information Science and Earth Observation (ITC), \\ Enschede, the Netherlands \\ ${ }^{4}$ 3D Optical Metrology (3DOM) Unit, Bruno Kessler Foundation (FBK), Trento, Italy \\ ${ }^{5}$ Department of Land, Environment, Agriculture and Forestry, University of Padova, Legnaro, Italy
}

Correspondence: Daniele Giordan (daniele.giordan@irpi.cnr.it)

Received: 21 September 2017 - Discussion started: 4 October 2017

Revised: 23 February 2018 - Accepted: 1 March 2018 - Published: 6 April 2018

\begin{abstract}
The number of scientific studies that consider possible applications of remotely piloted aircraft systems (RPASs) for the management of natural hazards effects and the identification of occurred damages strongly increased in the last decade. Nowadays, in the scientific community, the use of these systems is not a novelty, but a deeper analysis of the literature shows a lack of codified complex methodologies that can be used not only for scientific experiments but also for normal codified emergency operations. RPASs can acquire on-demand ultra-high-resolution images that can be used for the identification of active processes such as landslides or volcanic activities but can also define the effects of earthquakes, wildfires and floods. In this paper, we present a review of published literature that describes experimental methodologies developed for the study and monitoring of natural hazards.
\end{abstract}

\section{Introduction}

In the last three decades, the number of natural disasters showed a positive trend with an increase in the number of affected populations. Disasters not only affected the poor and characteristically more vulnerable countries but also those thought to be better protected. The Annual Disaster Statistical Review describes recent impacts of natural disasters on the population and reports 342 naturally triggered disasters in 2016 (Guha-Sapir et al., 2017). This is less than the an- nual average disaster frequency observed from 2006 to 2015 (376.4 events). However, natural disasters are still responsible for a high number of casualties (8733 death). In the period 2006-2015, the average number of causalities caused annually by natural disasters is 69827 . In 2016, hydrological disasters (177) had the largest share in natural disaster occurrence $(51.8 \%)$, followed by meteorological disasters $(96 ; 28.1 \%)$, climatological disasters $(38 ; 11.1 \%)$ and geophysical disasters $(31 ; 9.1 \%)$ (Guha-Sapir et al., 2017). To face these disasters, one of the most important solutions is the use of systems able to provide an adequate level of information for correctly understanding these events and their evolution. In this context, surveying and monitoring natural hazards gained importance. In particular, during the emergency phase it is very important to evaluate and control the phenomenon of evolution, preferably operating in near real time or real time, and consequently, use this information for a better risk assessment scenario. The available acquired data must be processed rapidly to support the emergency services and decision makers.

Recently, the use of remote sensing (satellite and airborne platform) in the field of natural hazards and disasters has become common, also supported by the increase in geospatial technologies and the ability to provide and process up-to-date imagery (Joyce et al., 2009; Tarolli, 2014). Remotely sensed data play an integral role in predicting hazard events such as floods and landslides, subsidence events and other ground instabilities. Because of their acquisition mode and capabil- 


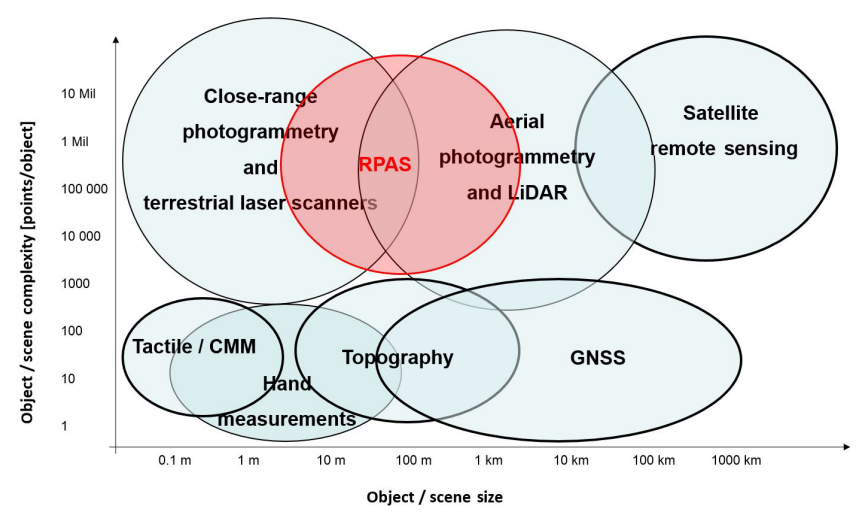

Figure 1. Available geomatics techniques, sensors and platforms for topographic mapping or detailed 3-D recording of ground information, according to scene dimensions and complexity (modified from Nex and Remondino, 2014).

ity for repetitive observations, the data acquired at different dates and high spatial resolution can be considered an effective complementary tool for field techniques to derive information on landscape evolution and activity over large areas.

In the context of remote-sensing research, recent technological developments have increased in the field of remotely piloted aircraft systems (RPASs), becoming more common and widespread in civil and commercial contexts (Bendea et al., 2008). In particular, the associated development of photogrammetry and technologies (i.e. integrated camera systems such as compact cameras, industrial grade cameras, video cameras, single-lens reflex (SLR) digital cameras and GNSS/INS systems) allow the use of RPAS platforms in various applications as an alternative to traditional remotesensing methods for topographic mapping or detailed 3-D recording of ground information and as a valid complementary solution to terrestrial acquisitions (Nex and Remondino, 2014) (Fig. 1).

RPAS systems present some advantages in comparison to traditional platforms and, in particular, they can be competitive thanks to their versatility in flight execution (Gomez and Purdie, 2016). Mini/micro RPASs are the most diffused for civil purposes, and they can fly at low altitudes according to limitations defined by national aviation security agencies and be easily transported into the disaster area. Foldable systems fit easily into a daypack and can be transported safely as hand luggage. This advantage is particularly important for first responder teams such as UNDAC (United Nations Disaster Assessment and Coordination). Stöcker et al. (2017) published a review of different state regulations that are characterized by several differences regarding requirements, distance from the take-off point and maximum altitude. Another important feature of RPASs is their adaptability, which allows for use in various types of missions, and in particular for monitoring operations in remote and dangerous areas (Obanawa et al., 2014). The possibility of carrying out flight operations at lower costs compared to ones required by traditional aircraft is also a fundamental advantage. Limited operating costs also make these systems convenient for multi-temporal applications where it is often necessary to acquire information on an active process (e.g. a landslide) over time. A comparison between the use of satellite images, traditional aircraft and RPASs has been presented and discussed by Fiorucci et al. (2018) for landslide applications and by Giordan et al. (2017) for the identification of flooded areas. These comparisons show that RPASs are a good solution for the ondemand acquisition of high-resolution images over limited areas.

RPASs are used in several fields such as agriculture, forestry, archaeology and architecture, traffic monitoring, environment and emergency management. In particular, in the field of emergency assistance and management, RPAS platforms are used to reliably and quickly collect data from inaccessible areas (Huang et al., 2017b). Collected data are mostly images but can also be gas concentrations or radioactivity levels as demonstrated by the tragic event in Fukushima (Sanada and Torii, 2015; Martin et al., 2016). Focusing on image collection, they can be used for early impact assessment, to inspect collapsed buildings and to evaluate structural damages on common infrastructures (Chou et al., 2010; Molina et al. 2012; Murphy et al., 2008; Pratt et al., 2009) or cultural heritage sites (Pollefeys et al., 2001; Manferdini et al., 2012; Koutsoudisa et al., 2014; Lazzari et al., 2017). Environmental and geological monitoring can profit from fast multi-temporal acquisitions delivering high-resolution images (Thamm and Judex, 2006; Niethammer et al., 2010). RPASs can also be considered a good solution for mapping and monitoring different active processes at the earth's surface (Fonstad et al., 2013; Piras et al., 2017; Feurer et al., 2017; Hayakawa et al., 2018) such as at glaciers (Immerzeel et al., 2014; Ryan et al., 2015; Fugazza et al., 2017), Antarctic moss beds (Lucieer et al., 2014b), coastal areas (Delacourt et al., 2009; Klemas, 2015), interseismic deformations (Deffontaines et al., 2017, 2018) and in river morphodynamics (Gomez and Purdie, 2016; Jaud et al., 2016; Aicardi et al., 2017; Bolognesi et al., 2016; Benassai et al., 2017), debris flows (Wen et al., 2011) and river channel vegetation (Dunford et al., 2009).

The incredible diffusion of RPASs has pushed many companies to develop dedicated sensors for these platforms. Besides the conventional RGB cameras other camera sensors are now available on the market. Multi- and hyperspectral cameras, as well as thermal sensors, have been miniaturized and customized to be hosted on many platforms.

The general workflow of a UAV (unmanned aerial vehicle) acquisition is presented in Fig. 2 below. The resolution of the images, the extension of the area and the goal of the flight are the main constraints that affect the selection of the platform and the type of sensor. Large areas can be flown over using fixed-wing (or hybrid) solutions that are able to acquire nadir images in a fast and efficient way. Images of 
small areas or complex objects (e.g. steep slopes or buildings) should be acquired using rotor RPASs. They are usually slower but they allow the acquisition of oblique views. If different information from the visible band is needed, the RPASs can host one or more sensors acquiring in different bands. The flight mission can be planned using dedicated software ranging from simple apps installed on smartphones in the low-cost solutions to laptops connected to directional antennas and remote controls for the most sophisticated platforms. According to the type of platform, different GNSS and IMU systems can be installed. Low-cost solutions are usually able to give positions within a few metres and need GCPs (ground control points) to georeference the images. In contrast, most expensive solutions install double-frequency GNSS receivers with the possibility of obtaining accurate georeferencing thanks to real-time kinematic (RTK) or postprocessing kinematic (PPK) corrections. The use of GCPs and different GNSS solutions is important. Gerke and Przybilla (2016) presented the effects of RTK GNSS and crossflight patterns, and Nocerino et al. (2013) presented an evaluation of the quality of RPAS processing results considering (i) the use of GCPs, (ii) different photogrammetric procedures and (iii) different network configurations. If a quick mapping is needed, the information delivered by the navigation system can be directly used to stitch the images and produce a rough image mosaicking (Chang-Chun et al., 2011). In the alternative scenario, a typical photogrammetric process is followed: (i) image orientation, (ii) DSM generation and (iii) orthophoto generation. The position (georeferencing) and the attitude (rotation towards the coordinates system) of each acquisition is obtained by estimating the image orientation. In the dense point cloud generation, 3-D point clouds are generated from a set of images, while the orthophoto is generated in the last step, combining the oriented images projected onto the generated point cloud, leading to orthorectified images (Turner et al., 2012). Point clouds can very often be converted into digital surface models (DSMs), and digital terrain models (DTMs) can be extracted by removing the off-ground regions (mainly buildings and trees). In real applications, many parameters can influence the final resolution of DSM/DTM and orthophotos such as real GSD (ground sample distance) (Nocerino et al., 2013) interior and exterior orientation parameters (Kraft et al., 2016), overlapping images, flight strip configuration and used SfM (Structure-from-Motion) software (Nex et al., 2015).

In particular during emergencies, the time required for the image data set processing can be critical. For this reason, fast mosaicking methods for real-time mapping applications (Lehmann et al., 2011), or VABENE ++, were developed by the German Aerospace Center for real-time traffic management (Detzer et al., 2015).

The outputs from the last two steps (point clouds and trueorthophotos), as well as the original images, are very often used as input in the scene understanding process: classification of the scene or extraction of features (i.e. objects)

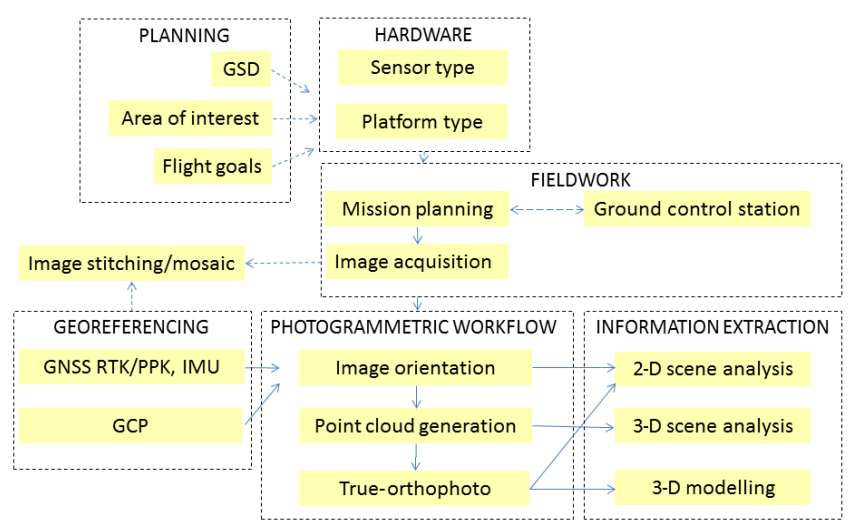

Figure 2. Acquisition and processing of RPAS images: general workflow.

of interest using machine-learning techniques are the most common applications. 3-D models can also be generated using the point cloud and the oriented images to texturize the model.

In this paper, the authors present an analysis and evaluation concerning the use of RPASs as alternative monitoring technique to traditional methods, which relate to the natural hazard scenarios. The main goal is to define and test the feasibility of a set of methodologies that can be used in monitoring and mapping activities. The study is focused in particular on the use of mini and micro RPAS systems (Table 1). The following table listed the technical specifications of these two RPAS categories, again based on the current classification by UVS (Unmanned Vehicle Systems) International. Most of the mini or micro RPAS systems available integrate a flight control system, which autonomously stabilizes these platforms and enables remotely controlled navigation. Additionally, they can integrate an autopilot, which allows autonomous flight based on predefined waypoints. For monitoring and mapping applications, mini or micro RPAS systems are very useful as cost-efficient platforms that capture real-time close-range imagery. These platforms can reach the area of investigation and take several photos and videos from several points of view (Gomez and Kato, 2014). For mapping applications, it is also possible to use this flight control data to georegister captured payload sensor data such as still images or video streams (Eugster and Nebiker, 2008).

\section{Use of RPASs for natural hazards detection and monitoring}

Gomez and Purdie (2016) published a detailed analysis of the use of RPASs for hazards and disaster risk monitoring. In our paper, we focused our attention on the most dangerous natural hazards that can be analysed using RPASs. According to the definitions used by the Annual Disaster Statistical Review (Guha-Sapir et al., 2017), the paper considers, in partic- 
Table 1. Classification of mini and micro UAV systems, according to UVS International (UVS International, 2018).

\begin{tabular}{lllll}
\hline Category & Max. take-off weight & Max. flight altitude & Endurance & Data link range \\
\hline Mini & $<30 \mathrm{~kg}$ & $150-300 \mathrm{~m}$ & $<2 \mathrm{~h}$ & $<10 \mathrm{~km}$ \\
Micro & $<5 \mathrm{~kg}$ & $250 \mathrm{~m}$ & $1 \mathrm{~h}$ & $<10 \mathrm{~km}$ \\
\hline
\end{tabular}

ular, (i) landslides, (ii) floods, (iii) earthquakes, (v) volcanic activity and (vi) wildfires. For each considered category of natural hazard, the paper presents a review of a large list of published papers (171 papers), analysing proposed methodologies, providing results and underlining strengths and limitations in the use of RPASs. The aims of this paper are to describe possible uses of RPASs in the considered natural hazards, to describe a general methodology for the use of these systems in different contexts and to merge all previously published experiences.

\subsection{Landslides}

Landslides are one of the major natural hazards that produce enormous property damage each year regarding both direct and indirect costs. Landslides are rock, earth or debris flows on slopes due to gravity. The event can be triggered by a variety of external elements, such as intense rainfall, water level change, storm waves or rapid stream erosion that cause a rapid increase in shear stress or decrease in shear strength of slope-forming materials. Moreover, the pressures of increasing population and urbanization and human activities such as deforestation or excavation of slopes for road cuts and building sites, etc. have become important triggers for landslide occurrence. Because the factors affecting landslides can be geophysical or human-made, they can occur in developed and undeveloped areas.

In the field of natural hazards, the use of RPASs for landslide studies and monitoring represents one of the most common applications. The number of papers that present case studies or possible methodologies dedicated to this topic have strongly increased in the last few years and now the available bibliography offers a good representation of possible approaches and technical solutions.

When a landslide occurs, the first information to be provided is the extent of the area affected by the event (Fig. 3). The landslide impact extent is usually analysed based on detailed optical images acquired after the event. From these acquisitions, it is possible to derive digital elevation models (DEMs) and orthophotos that allow major changes to be detected in geomorphological figures (Fan et al., 2017; Chang et al., 2018). In this scenario, the use of the mini and micro RPASs is practical for small areas and optimal for landslides that often cover an area that ranges from less than one square kilometres up to few square kilometres. Ultra-highresolution images acquired by RPASs can support the definition of not only the identification of studied landslide limit

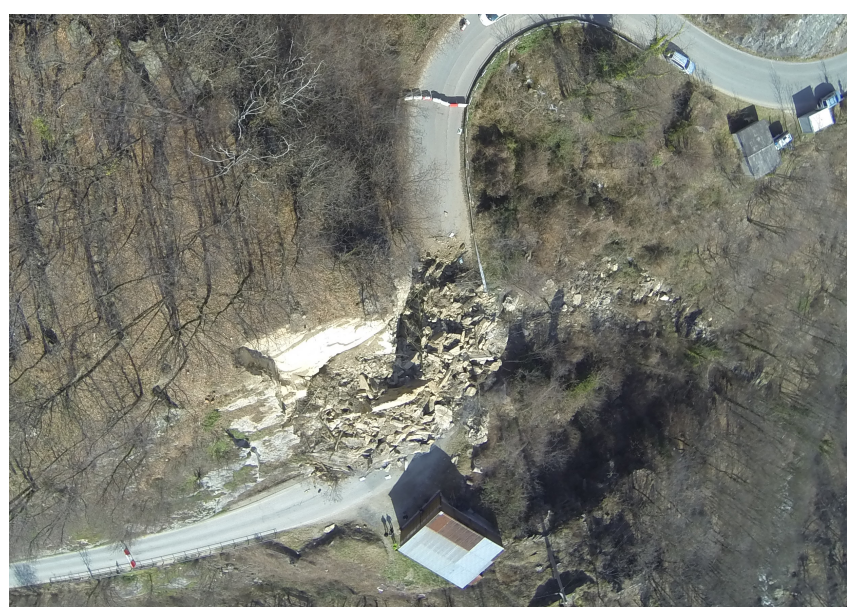

Figure 3. Example of RPAS image of a rockslide that occurred on a road. The image was acquired after the rockslide occurred in 2014 in San Germano municipality (Piemonte region, NW Italy). As presented in Giordan et al. (2015a), a multi-rotor of the local Civil Protection Agency was used to evaluate damages and residual risk. RPAS images can be very useful as a representation of the occurred phenomena from a different point of view. Even if it has not already been processed using SfM applications, this data set can be very useful for decision makers for defining the management strategy of the first emergency phase.

but also the identification and mapping of the main geomorphological features (Rossi et al., 2017; Fiorucci et al., 2018). Furthermore, a sequence of RPAS acquisitions over time can provide useful support for the study of gravitational process evolution.

According to Scaioni et al. (2014), applications of remote sensing for landslide investigations can be divided into three classes: (i) landside recognition, classification and post-event analysis, (ii) landslide monitoring and (iii) landslide susceptibility and hazard assessment.

\subsubsection{Landslide recognition}

The identification and mapping of landslides are usually performed after intense meteorological events that can activate or reactivate several gravitational phenomena. The identification and mapping of landslides can be organized into landslide event maps. Landslide event mapping is a wellknown activity obtained through field surveys (Yoon et al., 2012; Santangelo et al., 2010), visual interpretation of aerial or satellite images (Brardinoni et al., 2003; Ardizzone et 
al., 2013) and combined analysis of lidar DTM and images (Van Den Eeckhaut et al., 2007; Haneberg et al., 2008; Giordan et al., 2013; Razak et al., 2013; Niculiţa, 2016). The use of RPASs for the identification and mapping of a landslide has been described by several authors (Niethammer et al., 2009, 2010, 2011; Rau et al., 2011; Carvajal et al., 2011; Travelletti et al., 2012; Torrero et al., 2015; Casagli et al., 2017). Niethammer et al. (2009) and Liu et al. (2015) showed how RPASs could be considered a good solution for the acquisition of ultra-high-resolution images with low-cost systems. Fiorucci et al. (2018) compared the results of the landslide limitations mapped using different techniques and found that satellite images can be considered a good solution for the identification and mapping of landslides over large areas. On the contrary, if the target of the study is the definition of the landslide's morphological features, the use of more detailed RPAS images seemed to be the better solution. As suggested by Walter et al. (2009) and Huang et al. (2017a), one of the most critical elements for correct georeferencing of acquired images is the use of GCPs. The in situ installation and positioning acquisition of GCPs can be an important challenge, in particular in dangerous areas such as active landslides. Very often, GCPs are not installed in the most active part of the slide but on stable areas. This solution can be safer for the operator, but it can also reduce the accuracy of the final reconstruction.

Another parameter that can be considered during the planning of the acquisition phase is the morphology of the studied area. According to with Giordan et al. (2015b), slope materials and gradient can affect the flight planning and the approach used for the acquisition of the RPAS images. Two possible scenarios can be identified: (i) steep to vertical areas $\left(>40^{\circ}\right)$ and (ii) slopes with gentle-to-moderate slopes $\left(<40^{\circ}\right)$. In the first case, the use of multi-copters with oblique acquisitions is often the best solution. On the contrary, with more gentle slopes, the use of fixed-wing systems can assure the acquisition of larger areas.

\subsubsection{Landslide monitoring}

The second possible field of application of RPASs is the use of multi-temporal acquisitions for landslide monitoring. This topic has been described by several authors (Dewitte et al., 2008; Turner and Lucieer, 2013; Travelletti et al., 2012; Lucieer et al. 2014a; Turner et al., 2015; Marek et al., 2015; Lindner et al., 2016; Peppa et al., 2017). In these works, numerous techniques based on the multi-temporal comparison of RPAS data sets for the definition of the evolution of landslides have been presented and discussed. Niethammer et al. $(2010,2012)$ described how the position change of geomorphological features (in particular fissures) could be considered for a multi-temporal analysis with the aim of the characterization of the landslide evolution. Travelletti et al. (2012) introduced the possibility of a semi-automatic image correlation to improve this approach. The use of im- age correlation techniques has also been described by $\mathrm{Lu}-$ cieer et al. (2014a), who demonstrated that COSI-Corr (Coregistration of Optically Sensed Imaged and Correlation Leprince et al., 2007, 2008; Ayoub et al., 2009) can be adopted for the definition of the surface movement of the studied landslide. A possible alternative solution is a multitemporal analysis of the use of DSMs. The comparison of digital surface models can be used for the definition of volumetric changes caused by the evolution of the studied landslide. The acquisition of these digital models can be done with terrestrial laser scanners (Baldo et al., 2009) or airborne lidar (Giordan et al., 2013). Westoby et al. (2012) emphasized the advantages of RPASs concerning terrestrial laser scanners, which can suffer from line-of-sight issues, and airborne lidar, which are often cost-prohibitive for individual landslide studies. Turner et al. (2015) stressed the importance of a good co-registration of multi-temporal DSMs for good results that could decrease in accuracy. The use of benchmarks in areas not affected by morphological changes can be used for a correct calibration of rotational and translation parameters.

\subsubsection{Landslide susceptibility and hazard assessment}

Landslide susceptibility and hazard assessment are often performed at basin scale (Guzzetti et al., 2005) using different remote-sensing techniques (Van Westen et al., 2008). The use of RPASs can be considered for single case study applications to help decision makers in the identification of landslide damage and the definition of residual risk (Giordan et al., 2015a). Saroglou et al. (2018) presented the use of RPASs for the definition of trajectories of rockfall-prone areas. Salvini et al. $(2017,2018)$ and Török et al. (2018) described the combined use of TLS and RPASs for hazard assessment of steep rock walls. All these papers considered the use of RPASs as a valid solution for the acquisition of DSM over sub-vertical areas. Török et al. (2018) and Tannant et al. (2017) also described in their papers how RPAS DSMs can be used for the evaluation of slope stability using numerical modelling. Fan et al. (2017) analysed the geometrical features and provided the disaster assessment of a landslide that occurred on 24 June 2017 in the village of Xinmo in Maoxian County (Sichuan province, south-west China). Aerial images were acquired the day after the event from a UAV (fixed-wing $\mathrm{UAV}$, with a weight less than $10 \mathrm{~kg}$, and flight autonomy up to $4 \mathrm{~h}$ ), and a DEM was processed, with the purpose to analysed the main landslide geometrical features (front, rear edge elevation, accumulation area, horizontal sliding distance).

\subsection{Floods}

Disastrous floods in urban, lowland areas often cause fatalities and severe damage to the infrastructure. Monitoring the flood flow, assessment of the flood inundation areas and related damages, post-flood landscape changes and pre-flood 


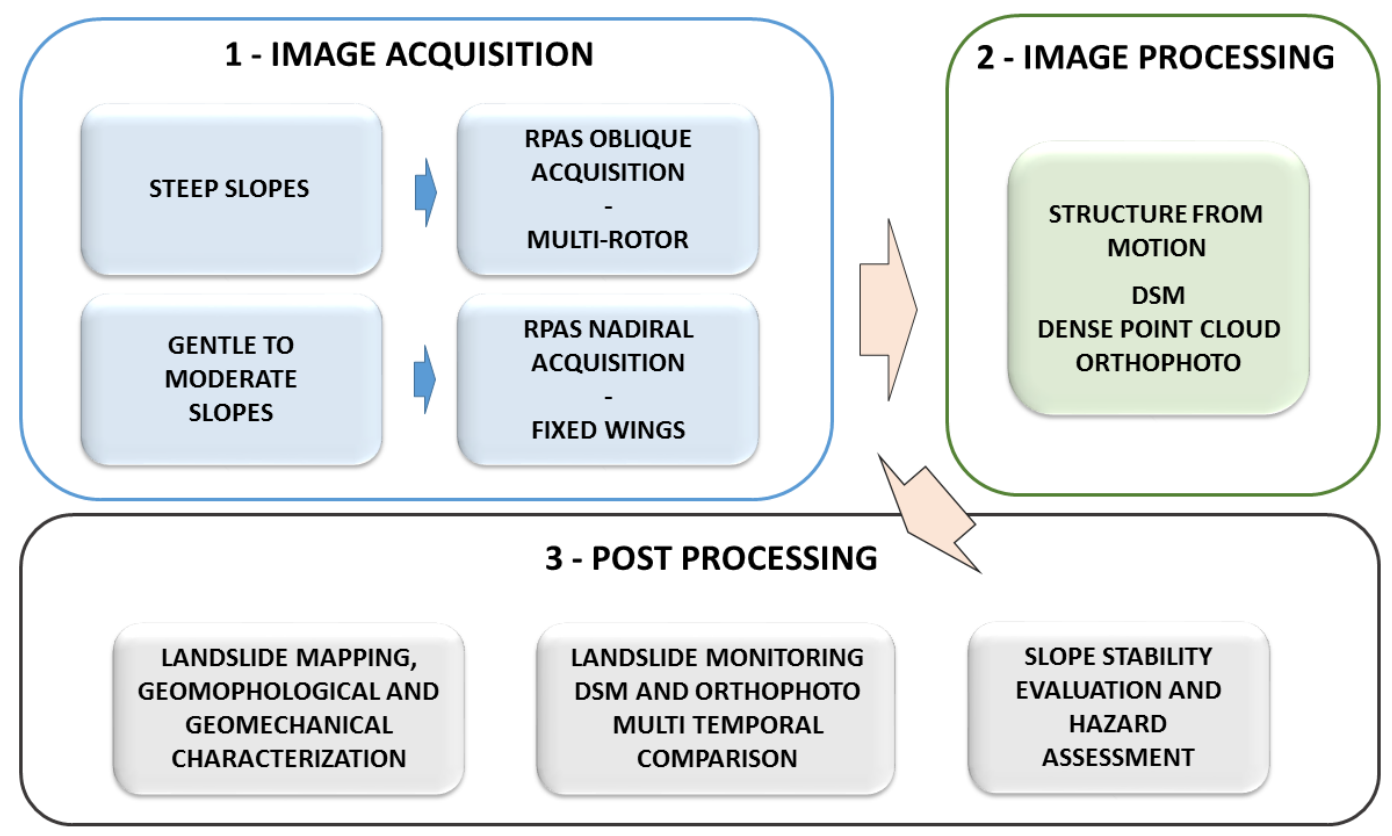

Figure 4. Acquisition, processing and post-processing of RPAS images applied to (i) landslide recognition, (ii) hazard assessment and (iii) slope evolution monitoring.

prediction are therefore urgently required. Among various scales of approaches for flood hazards (Sohn et al., 2008), the RPASs has been adopted for each purpose of the flood damage prevention and mitigation because it has the ability to take quick measurements at a low cost (DeBell et al., 2016; Nakamura et al., 2017). Figure 5 shows an example of the use of RPASs for prompt damage assessment by a severe flood occurred on early July 2017 in the northern Kyushu area, south-west Japan. The Geospatial Information Authority of Japan (GSI) utilized an RPAS for the post-flood video recording and photogrammetric mapping of the damaged area with flood flow and large woody debris.

\subsubsection{Potential analysis of flood inundation}

Risk assessment of flood inundation before the occurrence of a flood is crucial for the mitigation of the flood disaster damages. RPAS is capable of providing a quick and detailed analysis of the land surface information including topography, land cover and land use data, which are often incorporated into hydrological models for estimating floods (Costa et al., 2016). As a pre-flood assessment, Li et al. (2012) explored the area around an earthquake-derived barrier lake using an integrated approach of remote sensing with RPASs for hydrological analysis of the potential dam-break flood. They proposed a technical framework for real-time evacuation planning by accurately identifying the source water area of the dammed lake using an RPAS, followed by along-river hydrological computations of inundation potential. Tokarczyk et al. (2015) showed that the RPAS-derived imagery is use- ful for rainfall-run-off modelling for the risk assessment of floods by mapping detailed land-use information. As key input data, high-resolution imperviousness maps were generated for urban areas from RPAS imagery, which improved hydrological modelling for the flood assessment. Zazo et al. (2015) and Şerban et al. (2016) demonstrated hydrological calculations of potentially flood-prone areas using RPASderived 3-D models. They utilized 2-D cross profiles derived from the 3-D model for hydrological modelling.

\subsubsection{Flood monitoring}

Monitoring of the ongoing flood is potentially important for real-time evacuation planning. Le Coz et al. (2016) mentioned that videos captured by an RPAS, which can be operated not only by research specialists but also by general nonspecialists, are potentially useful for quantitatively monitoring floods as well as estimating flow velocity and modelling floods. They can also contribute to the crowd-sourced data collection for flood hydrology and citizen science. In the case of flood monitoring by image-based photogrammetry, however, areas under water are often problematic because the bed is not often fully seen in aerial images. If the water is clear enough, bed images under water can be captured, and the bed morphology can be measured with additional corrections of refraction (Tamminga et al., 2015; Woodget et al., 2015), but the floodwater is often unclear because of the abundant suspended sediment and disruptive flow current. Another option is the fusion of different data sets using a sonar-based measurement for the water-covered area, which is registered with 

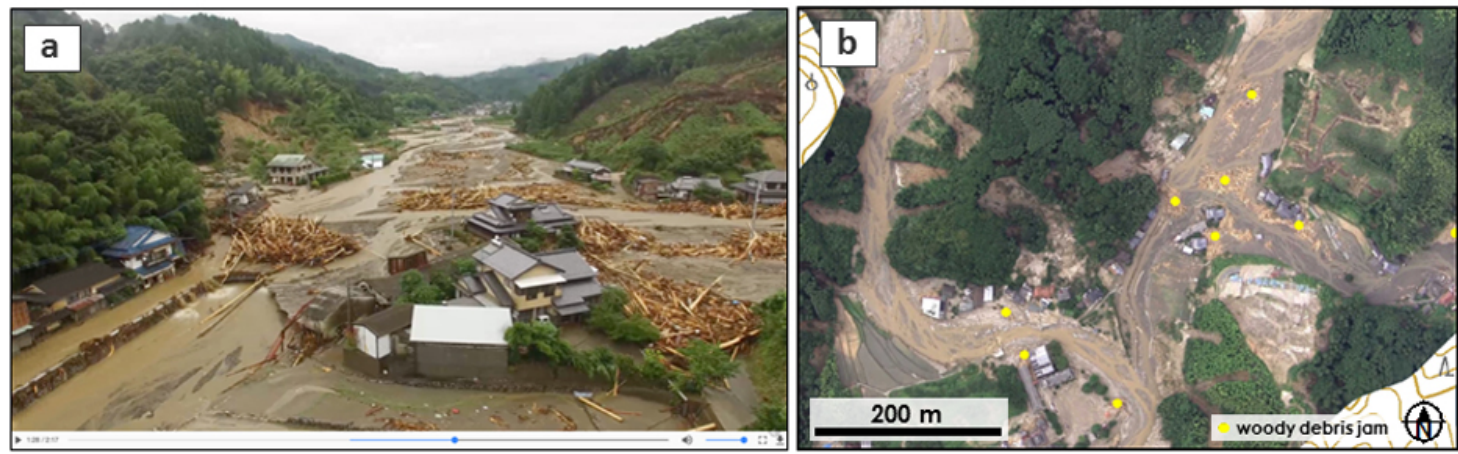

Figure 5. Image captures of a flood hazard using RPASs just after the 2017 heavy rain in northern Kyushu in early July (south-west Japan), provided by GSI. (a) A screenshot of the aerial video of a flooded area along the Akatani River, Asakura city in Fukuoka Prefecture. (b) Orthorectified image of the damaged area. Locations of woody debris jam are mapped and shown on the online map (GSI, 2017). The video and map products are freely provided (compatible with Creative Commons Attribution 4.0 International).

the terrestrial data sets (Flener et al., 2013; Javernick et al., 2014). Image-based topographic data of bottom water taken by an unmanned underwater vehicle (UUV, also known as an autonomous underwater vehicle, AUV) can also be another option (e.g. Pyo et al., 2015), although the application of UUV to flooding has been limited.

As well as the use of topographic data sets derived from Structure-from-Motion - Multi-View Stereo (SfM-MVS) photogrammetry, the use of orthorectified images concurrently derived from the RPAS-based aerial images is advantageous for the assessment of hydrological observation and modelling of floods. Witek et al. (2014) developed an experimental system to monitor the streamflow in real time to predict overbank flood inundation. The real-time prediction results are also visualized online with a web map service with a high-resolution image $\left(3 \mathrm{~cm} \mathrm{px}^{-1}\right)$. Feng et al. (2015) reported that the accurate identification of inundated areas is feasible using RPAS-derived images. In their case, deeplearning approaches of image classification using optical images and textures by RPASs successfully extracted the inundated areas, which must be useful for flood monitoring. Erdelj et al. (2017) proposed a system that incorporates multiple RPAS devices with wireless sensor networks to perform real-time assessment of a flood disaster. They discussed the technical strategies for real-time flood disaster management including the detection, localization, segmentation and size evaluation of flooded areas from RPAS-derived aerial images.

\subsubsection{Post-flood changes}

Post-flood assessments of the land surface materials including topography, sediment and vegetation are more feasible through RPAS surveys (Izumida et al., 2017). Smith et al. (2014) proposed a methodological framework for the immediate assessment of flood magnitude and affected landforms by SfM-MVS photogrammetry using both aerial and ground-based photographs. In this case, it is recommended to carefully select appropriate platforms for SfM-MVS photogrammetry (either airborne or ground based) based on the field conditions. Tamminga et al. (2015) examined the 3-D changes in river morphology due to an extreme flood event, revealing that the changes in reach-scale channel patterns of erosion and deposition are poorly modelled by the 2-D hydrodynamics based on the initial condition before the flood. They also demonstrate that the topographic condition can be more stable after an extreme flood event. Langhammer et al. (2017) proposed a method to quantitatively evaluate the grain size distribution using optical images taken by an RPAS, which is applied to the sediment structure before and after a flash flood.

In a relatively long-term study, Dunford et al. (2009) and Hervouet et al. (2011) explored annual landscape changes after the flood using RPAS-derived images together with other data sets such as satellite image archives or a manned motor paraglider. Their work assessed the progressive development of vegetation on a braided channel at an annual scale, which appears to be controlled by local climate including rainfall, humidity and air temperature, hydrology, groundwater level, topography and seed availability. Changes in the sediment characteristics due to flooding is another key feature to be examined.

\subsection{Earthquakes}

Remote-sensing technology has been recognized as a suitable source with which to provide timely data for automated detection of damaged buildings for large areas (Dong and Shan, 2013; Pham et al., 2014; Cannioto et al., 2017). In the post-event, satellite images have been traditionally used for decades to visually detect damage on the buildings to prioritize the interventions of rescuers. Operators search for externally visible damage evidence such as spalling, debris, rubble piles and broken elements, which represent strong indi- 

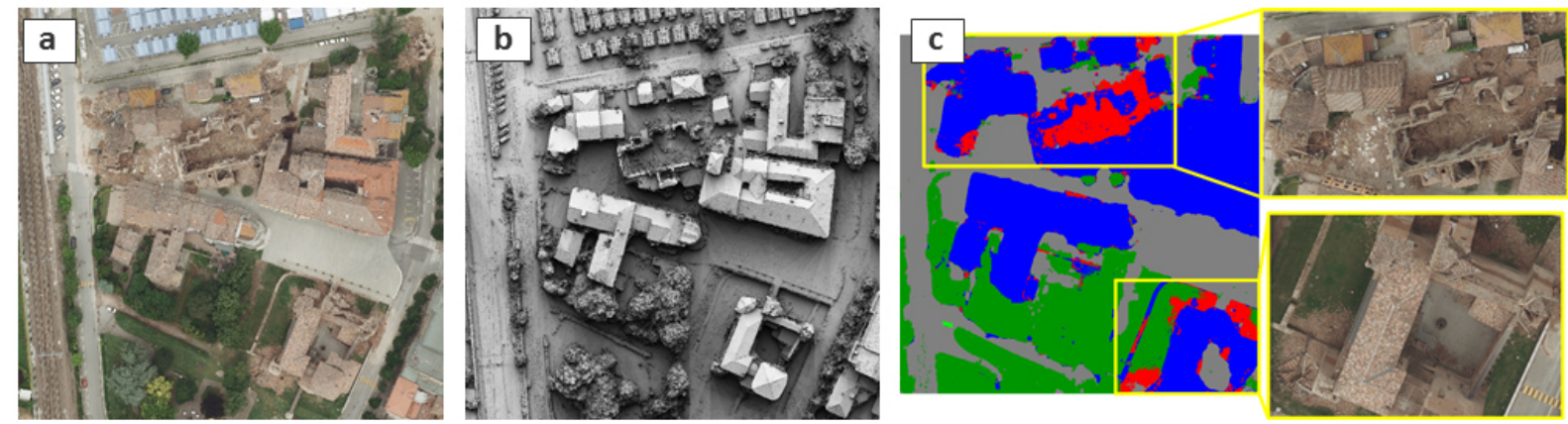

Figure 6. True orthophoto, digital surface model and damage map of an urban area using airborne nadir images (source: Nex et al., 2014).

cators of severe structural damage. Several studies, however, have demonstrated how this kind of data often leads to the wrong findings, usually underestimating the number of the collapsed buildings because of their reduced resolution on the ground. In this regard, airborne images and in particular oblique acquisitions (Tu et al., 2017; Nex et al., 2014; Gerke and Kerle, 2011; Nedjati et al., 2016) have demonstrated better input for reliable assessments, allowing the development of automated algorithms for this task (Fig. 6). The deployment of photogrammetric aeroplanes on the strike area is, however, very often unfeasible, especially when early (in the immediate hours after the event) damage assessment for response action is needed.

For this reason, RPASs have turned out to be valuable instruments for assessing damage to buildings (Hirose et al., 2015). The main advantages of RPASs are their availability (and reduced cost) and the ease at which they repeatedly acquire high-resolution images. Thanks to their high resolution, their use is not only limited to the early impact assessment for supporting rescue operations but is also considered in the preliminary analysis of the structural damage assessment.

\subsubsection{Early impact assessment}

The fast deployment in the field, the ease of use and the capability to provide real-time high-resolution information of inaccessible areas to prioritize the operator's activities are the strongest features of RPASs (Boccardo et al., 2015). The use of RPASs for rescue operations started almost a decade ago (Bendea et al., 2008) but their massive adoption began only in the last few years (earthquake in Nepal 2015) thanks to the development of low-cost and easy-to-use platforms. Initiatives such as UAViators (http://uaviators.org/, last access: 6 March 2018) have further increased public awareness and acceptance of this kind of instrument. Several rescue departments have now introduced RPASs as part of the conventional equipment of their teams (Xie et al., 2014). The huge number of videos acquired by RPASs and posted by rescuers online (i.e. on YouTube) after the 2016 Italian earthquakes confirm this general trend.
The operators use RPASs to fly over the area of interest and get information through visual assessment of the streaming videos. The quality of this analysis is therefore limited to the ability of the operator to fly the RPAS over the area of interest. The lack of video georeferencing usually reduces the interpretability of the scene and the accurate localization of the collapsed parts: only small regions can be acquired in a single flight. The lack of georeferenced maps prevents the smooth sharing of collected information with other rescue teams, limiting the practical exploitation of these instruments. RPASs are mainly used in daylight conditions as night-time flights are extremely dangeous, and the use of thermal images is of limited help to the rescuers.

Many researchers have developed algorithms to automatically extract damage information from imagery (Fig. 7). The main focus of these works is to reliably detect damage in a reduced time to satisfy the time constraints of the rescuers. In Vetrivel et al. (2015) the combined use of images and photogrammetric point clouds have shown promising results thanks to a supervised approach. This work, however, highlighted how the classifier and the designed 2-D and 3D features were hardly transferable to different data sets: each scene needed to be trained independently, strongly limiting the efficiency of this approach. In this regard, the recent developments in machine learning (i.e. convolutional neural networks, CNN) have overcome these limitations (Vetrivel et al., 2017), showing how they can correctly classify scenes even if they were trained using other data sets: a trained classifier can be directly used by rescuers on the acquired images without need for further operations. The drawback of these techniques is the computational time: the use of CNN processing such as image segmentation or point cloud generation is computationally demanding and hardly compatible with real-time needs (Brostow et al., 2008). In this regard, most recent solutions exploit only images (i.e. no need to generate point cloud) and limit the use of most expensive processes to the regions where faster classification approaches provide uncertain results to deliver almost real-time information (Duarte et al., 2017). 

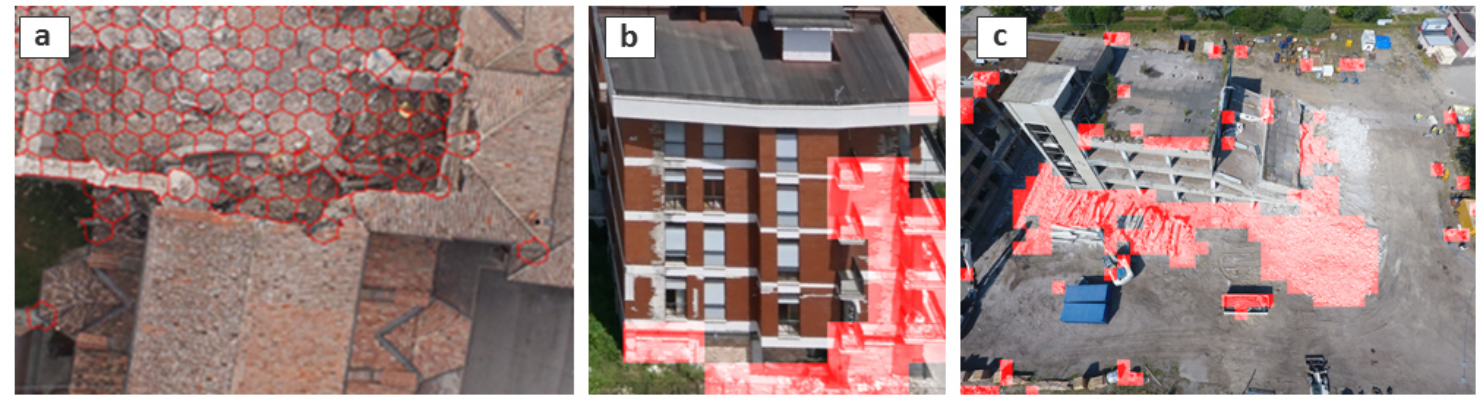

Figure 7. Examples of damage detection on images acquired in three different scenarios: (a) Mirabello (source: Vetrivel et al., 2017), (b) L'Aquila and (c) Lyon (source Duarte et al., 2017).

\subsubsection{Building damage assessment}

The damage evidence that can be captured from a UAV is not sufficient to infer the actual damage state of the building as it requires additional information such as damage to internal building elements (e.g. columns and beams) that cannot be directly defined from the images. Even though this information is limited, the images can provide useful information about the external condition of the structure, evidencing anomalies and damages and providing a first important piece of information for structural engineers. Two main types of investigation can be performed: (i) the use of images for the detection of cracks or damages on the external surfaces of the building (i.e. walls and roofs) and (ii) the use of point clouds (generated by photogrammetric approach) to detect structural anomalies such as tilted or deformed surfaces. In both cases, the automated processing can only support and ease the work of the expert, who still interprets and assesses the structural integrity of the building.

In Fernandez-Galarreta et al. (2015) a comprehensive analysis of both point clouds and images was presented to support the ambiguous classification of damages and their use for damage score. In this paper, the use of point clouds was considered efficient for more serious damages (partial or complete collapse of the building), while images were used to identify smaller damages such as cracks that can be used as the basis for the structural engineering analysis. The use of point clouds is investigated in Baiocchi et al. (2013) and Dominici et al. (2017): this contribution highlights how point clouds from UAVs can provide very useful information to detect asymmetries and small deformations of the structure.

\subsection{Volcanic activity}

RPASs are particularly advantageous when the target area of measurement is hardly accessible on the ground due to dangers of volcanic gas or risks of eruption in volcanic areas (Andrews, 2015). Although the equipment of RPASs can be lost or damaged by the volcanic activities, the operator can safely stay in a remote place. Various sensors can be mounted on an RPAS to monitor volcanic activities, including topog- raphy, land cover, heat, gas composition and even gravity field (Saiki and Ohba, 2010; Deurloo et al., 2012; Astuti et al., 2009; Middlemiss et al., 2016). The photogrammetric approach used to obtain topographic data is widely applied because RGB camera sensors are small enough to be mounted on a small aircraft. As mentioned before, this paper considers, in particular, small RPASs. In the study of volcanoes, larger aircraft with payloads of kilograms are also utilized to mount other types of sensors to monitor various aspects of their dynamic activities. For this reason, in this chapter, we also consider larger RPAS solutions.

\subsubsection{Topographic measurements of volcanoes}

A long-distance flight of an RPAS enables quick and safe measurements of an emerging volcanic island. Tobita et al. (2014a) successfully performed a fixed-wing RPAS oneway flight for a distance of $130 \mathrm{~km}$ and a total flight time of $2 \mathrm{~h}$ and $51 \mathrm{~min}$ over the sea to capture aerial images of a newly formed volcanic island next to Nishinoshima Island (Ogasawara Islands, south-west Pacific). They performed SfM-MVS photogrammetry of the aerial images taken from the RPAS to generate a $2.5 \mathrm{~m}$ resolution DEM of the island. The team also performed two successive measurements of Nishinoshima Island in the following 104 days, revealing that the morphological changes in the new island cover a $1600 \mathrm{~m}$ by $1400 \mathrm{~m}$ area (Nakano et al., 2014; Tobita et al., 2014b).

Since the volcanic activities often last for a long period, it is also important to connect the recent volcanic morphological changes to those in the past. Although detailed morphological data of volcanic topography are often unavailable, historical aerial photographs taken in the past decades can be utilized to generate topographic models at a certain resolution. Some case studies have used archival aerial photographs in volcanoes for periods of more than 60 years, generating DEMs with resolutions of several metres for areas of $10 \mathrm{~km}^{2}$ (Gomez, 2014; Derrien et al., 2015; Gomez et al. 2015). Although these DEMs are coarser than those derived from RPASs, they can be used as supportive data sets for modern morphological monitoring using RPASs at a higher resolution and measurement frequency. 


\subsubsection{Gas monitoring and product sampling}

Caltabiano et al. (2005) proposed the architecture of an RPAS for the direct monitoring of gas composition in volcanic clouds from Mt Etna in Italy. In this system, the $2 \mathrm{~m}$ wide fixed-wing RPASs can fly autonomously up to $4000 \mathrm{~m}$ altitude with a speed of $40 \mathrm{~km} \mathrm{~h}^{-1}$. Like this system, an RPAS with a payload of several kilograms can carry multiple sensors to monitor different compositions of volcanic gas. McGonigle et al. (2008) used an RPAS for volcanic gas measurements at the La Fossa crater of Mt Vulcano in Italy. The RPASs has a $3 \mathrm{~kg}$ payload and can host an ultraviolet spectrometer, an infrared spectrometer and an electrochemical sensor on board. The combination of these sensors enabled the estimation of fluxes of $\mathrm{SO}_{2}$ and $\mathrm{CO}_{2}$, which are crucial for revealing the geochemical condition of erupting volcanoes. The monitoring of gas composition including $\mathrm{CO}_{2}$, $\mathrm{SO}_{2}, \mathrm{H}_{2} \mathrm{~S}$ and $\mathrm{H}_{2}$, as well as air temperature, can be used for the quantification of the degassing activities and prediction of the conduit magma convection, as suggested by the tests at several volcanoes in Japan (Shinohara, 2013; Mori et al., 2016) and in Costa Rica (Diaz et al., 2015).

An RPAS can also transport a small ground-running robot (unmanned ground vehicle, UGV) to the slope head of an active volcano, where the UGV takes close-range photographs of volcanic ash on the ground surface by running down the slope (Nagatani et al., 2013). Protocols for direct sampling of volcanic products using an RPAS have also been developed (Yajima et al., 2014).

\subsubsection{Geothermal monitoring}

In New Zealand, Harvey et al. (2016) and Nishar et al. (2016) carried out experimental studies on the regular monitoring of intense geothermal environments using a small RPAS. They used thermal images taken by an infrared imaging sensor together with normal RGB images for photogrammetry, mapping both the ground surface temperature with detailed topography and land cover data. Chio and Lin (2017) further assessed the use of an RPAS equipped with a thermal infrared sensor for the high-resolution geothermal image mapping in a volcanic area in Taiwan. They improved the measurement accuracies using an on-board sensor capable of postprocessed kinematic GNSS positioning. This allows accurate mapping with fewer ground control points, which are hard to place on such intense geothermal fields.

\subsection{Wildfires}

Wildfires are a phenomenon with local and global effects (Filizzola et al., 2017). Wildfires represent a serious threat for land managers and property owners; in the last few years, this threat has significantly expanded (Peters et al., 2013). The literature also suggests that climate change will continue to enhance potential forest fire activity in different re- gions of the world (McKenzie et al., 2014; Abatzoglou and Williams, 2016). Remote-sensing technologies can be very useful in monitoring such hazards (Schroeder et al., 2016). Several scientists in the last few years used satellites in fire monitoring (Schroeder et al., 2016). More recently, RPASs have been considered to be useful as well (Martinez-de Dios et al., 2011). Hinkley and Zajkowski (2011) presented the results of a collaborative partnership between NASA and the US Forest Service established for testing thermal image data for wildfire monitoring. A small unmanned airborne system served as a sensor platform. The outcome was an improved tool for Wildland Fire Decision Support Systems. Merino et al. (2012) described a system for forest fire monitoring using an RPAS. The system integrates the information from the fleet of different vehicles to estimate the evolution of the forest fire in real time. The field tests indicated that RPASs could be very helpful in firefighting activities (e.g. monitoring). Indeed, they cover the gap between the spatial scales given by satellites and those based on cameras. Wing et al. (2014) underlined the fact that spectral and thermal sensors mounted in RPASs may hold great promise for future remote-sensing applications related to forest fires. RPASs have great potential to provide enhanced flexibility for positioning and repeated data collection. Tang and Shao (2015) summarize various approaches of remote drone sensing, surveying forests, mapping canopy gaps, measuring forest canopy height, tracking forest wildfires and supporting intensive forest management. These authors underlined the usefulness of drones for wildfire monitoring. RPASs can repeatedly fly to record the extent of an ongoing wildfire without jeopardizing the crew's safety. Zajkowski et al. (2015) tested different RPASs (e.g. quadcopter, fixed-wing) for the analysis of fire activity. Measurements included visible and long-wave infrared (LWIR) imagery, black carbon, air temperature, relative humidity and three-dimensional wind speed and direction. The authors also described the mission's plan in detail, including the logistics of integrating RPASs into a complex operations environment, specifications of the aircraft and their measurements, execution of the missions and considerations for future missions. Allison et al. (2016) provided a detailed state of the art on fire detection using both manned and unmanned aerial platforms. This review highlighted the following challenges: the need to develop robust automatic detection algorithms, the integration of sensors of varying capabilities and modalities, the development of best practices for the use of new sensor platforms (e.g. mini RPASs) and their safe and effective operation in the airspace around a fire.

\section{Discussion and conclusion}

In this paper, we analysed possible applications of RPASs to natural hazards. The available literature on this topic has strongly grown in the last few years, along with improvements in the diffusion of these systems. In particular, we 
considered landslides, floods, earthquakes, volcanic activities and wildfires.

RPASs can support studies on active geological processes and can be considered a good solution for the identification of effects and damages due to several catastrophic events. One of the most important elements that characterizes the use of RPASs is their flexibility, largely confirmed by the number of operative solutions available in the literature. The available literature pointed out the necessity of the development of dedicated methodologies that are able to take the full advantage of RPASs. In particular, typical results of Structurefrom-Motion software (orthophoto and DSM) that are considered the end of standard data-processing can very often be the starting point for dedicated procedures specifically conceived for natural hazard applications.

In the pre-emergency phase, one of the main advantages of RPAS surveys is to acquire high resolution and low-cost data to analyse and interpret environmental characteristics and potential triggering factors (e.g. slope, lithology, geostructure, land use/land cover, rock anomalies and displacement). The data can be collected with high revisit times to obtain multitemporal observations. After the characterization of hazard potential and vulnerability, some areas can be identified by a higher level of risk. These cases request intensive monitoring to gain a quantitative evaluation of the potential occurrence of an event. In this context, the use of aerial data represents a very useful complementary data source concerning the information acquired through ground-based observations, in particular for dangerous areas.

During the emergency phase, high-resolution imagery is acquired over the event site. The primary use of this data is for the assessment of the damage grade (extent, type and damage grades specific to the event and eventually of its evolution). They may also provide relevant information that is specific to critical infrastructure, transport systems, aid and reconstruction logistics, government and community buildings, hazard exposure, displaced population, etc. (Ezequiel et al., 2014). Concurrently, the availability of clear and straightforward raster and vector data, integrated with base cartographic contents (transportation, surface hydrology, boundaries, etc.) is recognized as an added value that supports decision makers for the management of emergency operations (Fikar et al., 2016). These applications very often need prompt and reliable interventions. RPASs should, therefore, deliver information promptly. In this regard, very few researchers have focused on this issue: most of the reported works present (often time consuming and even manual) postprocessing of the acquired data, precluding the use of their results from practical and real-life scenarios. Significant effort should be taken by the research community to propose faster and automated approaches. In particular during emergencies, the time required for RPAS data set processing is an important element that should be carefully considered. Giordan et al. (2015a) presented a case study related to a landslide emergency. In this paper, authors considered not only possible results but also the time that is required for them.

As in many other domains, RPASs present a disruptive technology in which, beside conventional SfM applications for 3-D reconstructions, many dedicated and advanced methodologies are still in their experimental phase and will need to be further developed in the coming years. In the following years, it would be desirable to witness the transfer of best practices in the use of RPASs be then from the research community to government agencies (or private companies) involved in the prevention and reduction of impacts of natural hazards. The scientific community should contribute to the definition of standard methodologies that can be assumed by civil protection agencies for the management of emergencies.

Data availability. No data sets were used in this article.

Competing interests. The authors declare that they have no conflict of interest.

Special issue statement. This article is part of the special issue "The use of remotely piloted aircraft systems (RPASs) in monitoring applications and management of natural hazards". It is a result of the EGU General Assembly 2016, Vienna, Austria, 17-22 April 2016.

Acknowledgements. We would like to thank the editor and two anonymous referees for their useful suggestions on our work.

Edited by: Uwe Ulbrich

Reviewed by: two anonymous referees

\section{References}

Abatzoglou, J. T. and Williams, A. P.: Impact of anthropogenic climate change on wildfire across western US forests, P. Natl. Acad. Sci. USA, 113, 11770-11775, 2016.

Aicardi, I., Chiabrando, F., Lingua, A., Noardo, F., Piras, M., and Vigna, B.: A methodology for acquisition and processing of thermal data acquired by UAVs: a test about subfluvial springs' investigations, Geomatics, Natural Hazards and Risk., 8, 5-17, https://doi.org/10.1080/19475705.2016.1225229, 2017.

Allison, R. S., Johnston, J. M., Craig, G., and Jennings, S.: Airborne Optical and Thermal Remote Sensing for Wildfire Detection and Monitoring, Sensors, 16, 1310, https://doi.org/10.3390/s16081310, 2016.

Andrews, C.: Pressure in the danger zone [volcanoes], Eng. Technol., 10, 56-61, https://doi.org/10.1049/et.2015.0720, 2015.

Ardizzone, F., Fiorucci, F., Santangelo, M., Cardinali, M., Mondini, A. C., Rossi, M., Reichenbach, P., and Guzzetti, F.: Very-high resolution stereoscopic satellite images for landslide mapping, 
edited by: Margottini, C., Canuti, P., Sassa, K., Landslide Science and Practice, Landslide Inventory and Susceptibility and Hazard Zoning, 1, Springer, Heidelberg, Berlin, New York, 95101, https://doi.org/10.1007/978-3-642-31325-7_12, 2013.

Astuti, G., Giudice, G., Longo, D., Melita, C. D., Muscato, G., and Orlando, A.: An overview of the "Volcan project": An UAS for Exploration of volcanic environments, J. Intell. Robot. Syst., 54, 471-494, 2009.

Ayoub, F., LePrince, S., and Keene, L.: User's Guide to Cosi-Corr: Co-Registration of Optically Sensed Images and Correlation, California Institute of Technology, Pasadena, CA, USA, 38 pp., 2009.

Baiocchi, V., Dominici, D., and Mormile, M.: UAV application in post-seismic environment", International Archives of the Photogrammetry, Remote Sensing and Spatial Information Sciences, Volume XL-1/W2, UAV-g2013, 4-6 September 2013, Rostock, Germany, 21-25, 2013.

Baldo M., Bicocchi C., Chiocchini U., Giordan D., and Lollino G.: LIDAR monitoring of mass wasting processes: The Radicofani landslide, Province of Siena, Central Italy, Gemorphology, 105, 193-201, https://doi.org/10.1016/j.geomorph.2008.09.015, 2009.

Benassai, G., Aucelli, P., Budillon, G., De Stefano, M., Di Luccio, D., Di Paola, G., Montella, R., Mucerino, L., Sica, M., and Pennetta, M.: Rip current evidence by hydrodynamic simulations, bathymetric surveys and UAV observation, Nat. Hazards Earth Syst. Sci., 17, 1493-1503, https://doi.org/10.5194/nhess17-1493-2017, 2017.

Bendea, H., Boccardo, P., Dequal, S., Tondo, G., Marenchino, D., and Piras, M.: Low cost UAV for post-disaster assessment, Int. Arch. Photogramm. Remote Sens. Spat. Inf. Sci., 37, 1373-1379, 2008.

Boccardo, P., Chiabrando, F., Dutto, F., Tonolo, F. G., and Lingua, A.: UAV deployment exercise for mapping purposes: Evaluation of emergency response applications, Sensors, 15, 15717-15737, 2015.

Bolognesi, M., Farina, G., Alvisi, S., Franchini, M., Pellegrinelli, A., and Russo, P.: Measurement of surface velocity in open channels using a lightweight remotely piloted aircraft system. Geomatics, Natural Hazards and Risk, 8, 73-86, https://doi.org/10.1080/19475705.2016.1184717, 2016.

Brardinoni, F., Slaymaker, O., and Hassan, M. A.: Landslides inventory in a rugged forested watershed: a comparison between air-photo and field survey data, Geomorphology, 54, 179-196, https://doi.org/10.1016/S0169-555X(02)00355-0, 2003.

Brostow, G. J., Shotton, J., Fauqueur, J., and Cipolla, R.: Segmentation and Recognition Using Structure from Motion Point Clouds. Proc. 10th European Conf. on Computer Vision: Part I, 44-57, https://doi.org/10.1007/978-3-540-88682-2_5, 2008.

Caltabiano, D., Muscato, G., Orlando, A., Federico, C., Giudice, G., and Guerrieri, S.: Architecture of a UAV for volcanic gas sampling, IEEE Int. C. Emerg., 1, 739-744, 2005.

Cannioto, M., D'Alessandro, A., Lo Bosco, G., Scudero, S., and Vitale, G.: Brief communication: Vehicle routing problem and UAV application in the post-earthquake scenario, Nat. Hazards Earth Syst. Sci., 17, 1939-1946, https://doi.org/10.5194/nhess17-1939-2017, 2017.
Carvajal, F., Agüera, F., and Pérez, M.: Surveying a landslide in a road embankment using Unmanned Aerial Vehicle photogrammetry, ISPRS Arch., 38, 1-6, 2011.

Casagli, N., Frodella, W., Morelli, S., Tofani, V., Ciampalini, A., Intrieri, E., Raspini, F., Rossi, G., Tanteri, L., and Lu, P.: Spaceborne, UAV and ground-based remote sensing techniques for landslide mapping, monitoring and early warning, Geoenvironmental Disasters, 4, 1-23, https://doi.org/10.1186/s40677-0170073-1, 2017.

Chang, K.-J., Chan, Y.-C., Chen, R.-F., and Hsieh, Y.-C.: Geomorphological evolution of landslides near an active normal fault in northern Taiwan, as revealed by lidar and unmanned aircraft system data, Nat. Hazards Earth Syst. Sci., 18, 709-727, https://doi.org/10.5194/nhess-18-709-2018, 2018.

Chang-Chun, L., Zhang, G., Lei, T., and Gong, A.: Quick imageprocessing method of UAV without control points data in earthquake disaster area, T. Nonferr. Metal. Soc., 21, s523-s528, 2011.

Chio, S.-H. and Lin, C.-H.: Preliminary Study of UAS Equipped with Thermal Camera for Volcanic Geothermal Monitoring in Taiwan, Sensors, 17, 1649, https://doi.org/10.3390/s17071649, 2017.

Chou, T. Y., Yeh, M. L., Chen, Y., and Chen, Y. H.: Disaster monitoring and management by the unmanned aerial vehicle technology, Int. Archives of Photogrammetry, Remote Sensing and Spatial Information Sciences, 38, 137-142, 2010.

Costa, D., Burlando, P., and Priadi, C.: The importance of integrated solutions to flooding and water quality problems in the tropical megacity of Jakarta, Sustain. Cities Soc., 20, 199-209, https://doi.org/10.1016/j.scs.2015.09.009, 2016.

DeBell, L., Anderson, K., Brazier, R. E., King, N., and Jones, L.: Water resource management at catchment scales using lightweight UAVs: current capabilities and future perspectives, J. Unmanned Veh. Syst., 4, 7-30, https://doi.org/10.1139/juvs2015-0026, 2016.

Deffontaines, B., Chang, K. J., Champenois, J., Fruneau, B., Pathier, E., Hu, J. C., Lu, S. T., and Liu, Y. C.: Active interseismic shallow deformation of the Pingting terraces (Longitudinal Valley - Eastern Taiwan) from UAV high-resolution topographic data combined with InSAR time series, Geomatics, Natural Hazards and Risk, 8, 120-136, 2017.

Deffontaines, B., Chang, K.-J., Champenois, J., Lin, K.-C., Lee, C.T., Chen, R.-F., Hu, J.-C., and Magalhaes, S.: Active tectonics of the onshore Hengchun Fault using UAS DSM combined with ALOS PS-InSAR time series (Southern Taiwan), Nat. Hazards Earth Syst. Sci., 18, 829-845, https://doi.org/10.5194/nhess-18829-2018, 2018.

Delacourt, C., Allemand, P., Jaud, M., Grandjean, P., Deschamps, A., Ammann, J., Cuq, V., and Suanez, S.: DRELIO: An Unmanned Helicopter for Imaging Coastal Areas. J. Coastal. Res., 56, 1489-1493, 2009.

Derrien, A., Villeneuve, N., Peltier, A., and Beauducel, F.: Retrieving 65 years of volcano summit deformation from multitemporal structure from motion: The case of Piton de la Fournaise (La Réunion Island), Geophys. Res. Lett., 42, 6959-6966, https://doi.org/10.1002/2015GL064820, 2015.

Deurloo, R., Bastos, L., and Bos, M.: On the Use of UAVs for Strapdown Airborne Gravimetry, Springer, Berlin, Heidelberg, 255261, 2012. 
Detzer, S., Weber, M., Touko Tcheumadjeu, L. C., Kuhns, G., and Kendziorra A.: Decision support for multimodal transportation systems at major events and disasters: a case study in the region of Brunswick (Germany), edited by: Sener, S. M., Brebbia, C. A., and Ozcevik, O., Disaster management and Human Health Risk IV, WIT Press, Southampton, UK, 315-326, 2015.

Dewitte, O., Jasselette, J. C., Cornet, Y., Van Den Eeckhaut, M., Collignon, A., Poesen, J., and Demoulin, A.: Tracking landslide displacements by multitemporal DTMs: A combined aerial stereophotogrammetric and LIDAR approach in western Belgium, Eng. Geol., 7, 582-586, 2008.

Diaz, J. A., Pieri, D., Wright, K., Sorensen, P., Kline-Shoder, R., Arkin, C. R., Fladeland, M., Bland, G., Buongiorno, M. F., Ramirez, C., Corrales, E., Alan, A., Alegria, O., Diaz, D., and Linick, J.: Unmanned Aerial Mass Spectrometer Systems for InSitu Volcanic Plume Analysis, J. Am. Soc. Mass Spectr., 26, 292-304, https://doi.org/10.1007/s13361-014-1058-x, 2015.

Dominici, D., Alicandro, M., and Massimi, V.: UAV photogrammetry in the post-earthquake scenario: case studies in L'Aquila, Geomatics, Natural Hazards and Risk, 8, 87-103, 2017.

Dong, L. and Shan, J.: A comprehensive review of earthquakeinduced building damage detection with remote sensing techniques, ISPRS Journal of Photogrammetry and Remote Sensing, 84, 85-99, 2013.

Duarte, D., Nex, F., Kerle, N., and Vosselman, G.: TOWARDS A MORE EFFICIENT DETECTION OF EARTHQUAKE INDUCED FAÇADE DAMAGES USING OBLIQUE UAV IMAGERY, Int. Arch. Photogramm. Remote Sens. Spatial Inf. Sci., XLII-2/W6, 93-100, https://doi.org/10.5194/isprs-archivesXLII-2-W6-93-2017, 2017.

Dunford, R., Michel, K., Gagnage, M., Piégay, H., and Trémelo M.L.: Potential and constraints of Unmanned Aerial Vehicle technology for the characterization of Mediterranean riparian forest, Int. J. Remote Sens., 30, 4915-4935, 2009.

Erdelj, M., Król, M., and Natalizio, E.: Wireless Sensor Networks and Multi-UAV systems for natural disaster management, Comput. Networks, 124, 72-86, https://doi.org/10.1016/j.comnet.2017.05.021, 2017.

Eugster, H. and Nebiker, S.: UAV-based augmented monitoringreal-time georeferencing and integration of video imagery with virtual globes. In: Int. Archives of Photogrammetry, Remote Sensing and Spatial Information Sciences, Beijing, China, 37, 1229-1235. 2008.

Ezequiel, C. A. F., Cua, M., Libatiquem, N. C., Tangonan, G. L., Alampay, R., Labuguen, R. T., Favila, C. M., Honrado, J. L. E., Canos, V., Devaney, C., Loreto, L. B., Bacusmo, J., and Palma, B.: UAV Aerial Imaging Applications for Post-Disaster Assessment, Environmental Management and Infrastructure Development. 2014 International Conference on Unmanned Aircraft Systems (ICUAS) Orlando, Fl, USA proceedings, 274-283, 2014.

Fan, J., Zhang, X., Su, F., Ge, Y., Tarolli, P., Yang, Z., Zeng, C., and Zeng, Z.: Geometrical feature analysis and disaster assessment of the Xinmo landslide based on remote sensing data, J. Mt. Sci., 14, 1677-1688, https://doi.org/10.1007/s11629-017-4633-3, 2017.

Feng, Q., Liu, J., and Gong, J.: Urban Flood Mapping Based on Unmanned Aerial Vehicle Remote Sensing and Random Forest Classifier - A Case of Yuyao, China, Water, 7, 1437-1455, https://doi.org/10.3390/w7041437, 2015.
Fernandez Galarreta, J., Kerle, N., and Gerke, M.: UAV-based urban structural damage assessment using object-based image analysis and semantic reasoning, Nat. Hazards Earth Syst. Sci., 15, 1087 1101, https://doi.org/10.5194/nhess-15-1087-2015, 2015.

Feurer, D., Planchon, O., El Maaoui, M. A., Boussema, M. R., and Pierrot-Deseilligny, M.: Potential of kite-borne photogrammetry for decimetric and kilometre square 3D mapping: an application for automatic gully detection, Nat. Hazards Earth Syst. Sci. Discuss., https://doi.org/10.5194/nhess-2017-60, in review, 2017.

Fikar, C., Gronalt, M., and Hirsch. P. A.: decision support system for coordinated disaster relief distribution, Exp. Syst. Appl., 57, 104-116, https://doi.org/10.1016/j.eswa.2016.03.039, 2016.

Filizzola, C., Corrado, R., Marchese, F., Mazzeo, G., Paciello, R., Pergola, N., and Tramutoli, V.: RST-FIRES, an exportable algorithm for early-fire detection and monitoring: Description, implementation, and field validation in the case of the MSG-SEVIRI sensor, Remote Sens. Environ., 192, 2-25, 2017.

Fiorucci, F., Giordan, D., Santangelo, M., Dutto, F., Rossi, M., and Guzzetti, F.: Criteria for the optimal selection of remote sensing optical images to map event landslides, Nat. Hazards Earth Syst. Sci., 18, 405-417, https://doi.org/10.5194/nhess-18-4052018, 2018.

Flener, C., Vaaja, M., Jaakkola, A., Krooks, A., Kaartinen, H., Kukko, A., Kasvi, E., Hyyppä, H., Hyyppä, J., and Alho, P. Seamless mapping of river channels at high resolution using mobile liDAR and UAV-photography, Remote Sens., 5, 6382-6407, https://doi.org/10.3390/rs5126382, 2013.

Fonstad, M. A., Dietrich, J. T., Courville, B. C., Jensen J. L., and Carbonneau, P. E.: Topographic structure from motion: a new development in photogrammetric measurement, Earth Surf. Proc. Land., 38, 421-430, 2013.

Fugazza, D., Scaioni, M., Corti, M., D’Agata, C., Azzoni, R. S., Cernuschi, M., Smiraglia, C., and Diolaiuti, G. A.: Combination of UAV and terrestrial photogrammetry to assess rapid glacier evolution and conditions of glacier hazards, Nat. Hazards Earth Syst. Sci. Discuss., https://doi.org/10.5194/nhess-2017-198, in review, 2017.

Gerke, M. and Kerle, N.: Automatic structural seismic damage assessment with airborne oblique pictometry imagery, in: PE\&RS = Photogrammetric Engineering and Remote Sensing, 77, 885-898, 2011.

Gerke, M. and Przybilla, H. J.: Accuracy analysis of photogrammetric UAV image blocks: Influence of on-board RTK-GNSS and cross flight patterns, Photogramm. Fernerkun., 2016, 17-30, 2016.

Giordan, D., Allasia, P., Manconi, A., Baldo, M., Santangelo, M., Cardinali, M., Corazza, A., Albanese, V., Lollino, G., and Guzzetti, F.: Morphological and kinematic evolution of a large earthflow: The Montaguto landslide, southern Italy, Geomorphology, 187, 61-79, 2013.

Giordan, D., Manconi, A., Facello, A., Baldo, M., dell'Anese, F., Allasia, P., and Dutto, F.: Brief Communication: The use of an unmanned aerial vehicle in a rockfall emergency scenario, Nat. Hazards Earth Syst. Sci., 15, 163-169, https://doi.org/10.5194/nhess-15-163-2015, 2015a.

Giordan, D., Manconi, A., Tannant, D., and Allasia, P.: UAV: lowcost remote sensing for high-resolution investigation of landslides, IEEE International Symposium on Geoscience and Re- 
mote Sensing IGARSS, 26-31 July 2015, Milan, Italy, 53445347, 2015b.

Giordan, D., Notti, D., Villa, A., Zucca, F., Calò, F., Pepe, A., Dutto, F., Pari, P., Baldo, M., and Allasia, P.: Low cost, multiscale and multi-sensor application for flooded areas mapping, Nat. Hazards Earth Syst. Sci. Discuss., https://doi.org/10.5194/nhess2017-420, in review, 2017.

Gomez, C.: Digital photogrammetry and GIS-based analysis of the bio-geomorphological evolution of Sakurajima Volcano, diachronic analysis from 1947 to 2006, J. Volcanol. Geoth. Res., 280, 1-13, https://doi.org/10.1016/j.jvolgeores.2014.04.015, 2014.

Gomez, C. and Kato, A.: Multi-scale voxel-based algorithm for UAV-derived point-clouds of complex surfaces, IEEE International ICARES - Aerospace Electornics and Remote Sensing Technology, 205-209, https://doi.org/10.1109/ICARES.2014.7024399, 2014.

Gomez, C. and Purdie, H.: UAV- based Photogrammetry and Geocomputing for Hazards and Disaster Risk Monitoring - A Review, Geoenvironmental Disasters, 3, 1-11, 2016.

Gomez, C., Hayakawa, Y., and Obanawa, H.: A study of Japanese landscapes using structure from motion derived DSMs and DEMs based on historical aerial photographs: New opportunities for vegetation monitoring and diachronic geomorphology, Geomorphology, 242, 11-20, https://doi.org/10.1016/j.geomorph.2015.02.021, 2015.

GSI: Information on the 2017 Northern Kyushu Heavy Rain, Geospatial Inf. Auth. Japan, available from: http://www.gsi. go.jp/BOUSAI/H29hukuoka_ooita-heavyrain.html, last access: 16 September 2017.

Guha-Sapir, D., Hoyois, P., Wallemacq, P., and Below, R.: Annual Disaster Statistical Review 2016 The numbers and trends. Centre for Research on the Epidemiology of Disasters, Ciaco Imprimerie, Louvain-la-Neuve (Belgium), 91, 2017.

Guzzetti, F., Reichenbach, P., Cardinali, M., Galli, M., and Ardizzone, F.: Probabilistic landslide hazard assessment at the basin scale, Geomorphology, 72, 272-299, 2005.

Haneberg, W. C.: Using close range terrestrial digital photogrammetry for 3-D rock slope modeling and discontinuity mapping in the United States, B. Eng. Geol. Environ., 67, 457-469, 2008.

Harvey, M. C., Rowland, J. V., and Luketina, K. M.: Drone with thermal infrared camera provides high resolution georeferenced imagery of the Waikite geothermal area, New Zealand, J. Volcanol. Geoth. Res., 325, 61-69, https://doi.org/10.1016/j.jvolgeores.2016.06.014, 2016.

Hayakawa, Y. S., Yoshida, H., Obanawa, H., Naruhashi, R., Okumura, K., Zaiki, M., and Kontani, R.: Characteristics of debris avalanche deposits inferred from source volume estimate and hummock morphology around Mt. Erciyes, central Turkey, Nat. Hazards Earth Syst. Sci., 18, 429-444, https://doi.org/10.5194/nhess-18-429-2018, 2018.

Hervouet, A., Dunford, R., Piégay, H., Belletti, B., and Trémélo, M.-L.: Analysis of Post-flood Recruitment Patterns in BraidedChannel Rivers at Multiple Scales Based on an Image Series Collected by Unmanned Aerial Vehicles, Ultra-light Aerial Vehicles, and Satellites, Geosci. Remote Sens., 48, 50-73, 2011.

Hinkley, E. and Zajkowski, T.: USDA forest service-NASA: unmanned aerial systems demonstrations-pushing the leading edge in fire mapping, Geocarto Int., 26, 103-111, 2011.
Hirose, M., Xiao, Y., Zuo, Z., Kamat, V. R., Zekkos, D., and Lynch, J.: Implementation of UAV localization methods for a mobile post-earthquake monitoring system, in: 2015 IEEE Workshop on Environmental, Energy, and Structural Monitoring Systems (EESMS) Proceedings, 66-71, 2015.

Huang, H., Long, J., Lin, H., Zang, L., Yi, W., and Lei, B.: Unmanned aerial vehicle based remote sensing method for monitoring a steep mountainous slope in the Three Gorges Reservoir, China, Earth Sci. Inform., 10, 287-301, 2017a.

Huang, H., Long, J., Yi, W., Yi, Q., Zhang, G., and Lei, B.: A method for using unmanned aerial vehicles for emergency investigation of single geo-hazards and sample applications of this method, Nat. Hazards Earth Syst. Sci., 17, 1961-1979, https://doi.org/10.5194/nhess-17-1961-2017, 2017b.

Immerzeel, W. W., Kraaijenbrink, P. D. A., Shea, J. M., Shrestha, A. B., Pellicciotti, F., Bierkens, M. F. P., and de Jonga, S. M.: High-resolution monitoring of Himalayan glacier dynamics using unmanned aerial vehicles, Remote Sens. Environ., 150, 93 103, 2014.

Izumida, A., Uchiyama, S., and Sugai, T.: Application of UAV-SfM photogrammetry and aerial lidar to a disastrous flood: repeated topographic measurement of a newly formed crevasse splay of the Kinu River, central Japan, Nat. Hazards Earth Syst. Sci., 17, 1505-1519, https://doi.org/10.5194/nhess-17-1505-2017, 2017.

Jaud, M., Grasso, F., Le Dantec, N., Verney, R., Delacourt, C., Ammann, J., Deloffre, J., and Grandjean, P.: Potential of UAVs for Monitoring Mudflat Morphodynamics (Application to the Seine Estuary, France), ISPRS Int. J. Geo-Inf., 5, 50, https://doi.org/10.3390/ijgi5040050,, 2016.

Javernick, L., Brasington, J., and Caruso, B.: Modeling the topography of shallow braided rivers using Structure-fromMotion photogrammetry, Geomorphology, 213, 166-182, https://doi.org/10.1016/j.geomorph.2014.01.006, 2014.

Joyce, K. E., Belliss, S. E., Samsonov, S. V., McNeill, S. J., and Glassey, P. J.: A review of the status of satellite remote sensing and image processing techniques for mapping natural hazards and disasters, Prog. Phys. Geog., 33, 83-207, 2009.

Kraft, T., Geßner, M., Meißner, H., Cramer, M., Gerke, M., and Przybilla, H. J.: Evaluation of a metric camera system tailored for high precision UAV applications, in: Proceedings of the XXIII ISPRS Congress : From human history to the future with spatial information, 12-19 July 2016, Prague, Czech Republic. Peer reviewed Annals, Volume III-2, 2016, Comm II, ThS14 recent developments in Open Data - Prague, Vol. XLI-B1, ISSN 21949034, 2016.

Klemas, V. V.: Coastal and Environmental Remote Sensing from Unmanned Aerial Vehicles: An Overview, J. Coastal. Res., 31, 1260-1267, 2015.

Koutsoudisa, A., Vidmarb, B., Ioannakisa, G., Arnaoutogloua, F., Pavlidis, V., and Chamzasc, C.: Multi-image 3D reconstruction data evaluation, J. Cult. Herit., 15, 73-79, 2014.

Lazzari, M. and Gioia, D.: UAV images and high-resolution DEMs for geomorphological analysis and hazard evaluation: the case of the Uggiano archaeological site (Ferrandina, southern Italy), Geomatics, Natural Hazards and Risk, 8, 104-119, 2017.

Langhammer, J., Lendzioch, T., Miřijovskyý, J., and Hartvich, F.: UAV-based optical granulometry as tool for detecting changes in structure of flood depositions, Remote Sens., 9, 240, https://doi.org/10.3390/rs9030240, 2017. 
Le Coz, J., Patalano, A., Collins, D., Guillén, N. F., García, C. M., Smart, G. M., Bind, J., Chiaverini, A., Le Boursicaud, R., Dramais, G., and Braud, I.: Crowdsourced data for flood hydrology: Feedback from recent citizen science projects in Argentina, France and New Zealand, J. Hydrol., 541, 766-777, https://doi.org/10.1016/j.jhydrol.2016.07.036, 2016.

Lehmann, F., Berger, R., Brauchle, J., Hein, D., Meißner, H., and Pless, S.: MACS - Modular Airborne Camera System for generating photogrammetric high-resolution products, Zeitschrift der Deutschen Gesellschaft für Geowissenschaften, Schweizerbart Science Publishers, Stuttgart, Germany, 435-446, 2011.

Leprince, S., Barbot, S., Ayoub, F., and Ayouac, J. P.: Automatic and precise orthorectification, co-registration, and sub-pixel correlation of satellite images, application to ground deformation measurements, IEEE T. Geosci. Remote, 46, 1529-1558, 2007.

Leprince, S., Berthier, E., Ayoub, F., Delacourt, C., and Avouac, J.-P.: Monitoring Earth Surface Dynamics With Optical Imagery, EOS T. Am. Geophys. Un., 89, 1-2, https://doi.org/10.1029/2008EO010001, 2008.

Li, Y., Gong, J. H., Zhu, J., Ye, L., Song, Y. Q., and Yue, Y. J.: Efficient dam break flood simulation methods for developing a preliminary evacuation plan after the Wenchuan Earthquake, Nat. Hazards Earth Syst. Sci., 12, 97-106, https://doi.org/10.5194/nhess-12-97-2012, 2012.

Lindner, G., Schraml, K., Mansberger, R., and Hubl, J.: UAV monitoring and documentation of a large landslide, Appl Geomat., 8, 1-11, 2016.

Liu, C.-C., Chen, P.-L., Tomoya, M., and Chen, C.-Y.: Rapidly responding to landslides and debris flow events using a lowcost unmanned aerial vehicle, J. Remote Sens. 9, 1-11, https://doi.org/10.1117/1.JRS.9.096016, 2015.

Lucieer, A., de Jong, S. M., and Turner, D.: Mapping landslide displacements using Structure from Motion (SfM) and image correlation of multi-temporal UAV photography, Prog, Phys. Geog., 38, 97-116, 2014a.

Lucieer, A., Turner, D., King, D. H., and Robinson, S. A.: Using an Unmanned Aerial Vehicle (UAV) to capture microtopography of Antarctic moss beds. Int. J. Appl. Earth Obs.. 27, 53-62, 2014 b.

Manferdini, A., Baroncini V., and Corsi, C.: An integrated and automated segmentation approach to deteriorated regions recognition on 3D reality-based models of cultural heritage artifacts, J. Cult. Herit., 13, 371-378, 2012.

Marek, L., Miřijovský, J., and Tuček, P.: Monitoring of the Shallow Landslide Using UAV Photogrammetry and Geodetic Measurements, in: Engineering Geology for Society and Territory Landslide Processes, edited by: Lollino, G., Giordan, D., Crosta, G. B., Corominas, J., Azzam, R. Wasowski, J., and Sciarra, N., Springer International Publishing, Switzerland, 2, 113-116, 2015.

Martin, P. G., Smith, N. T., Yamashiki, Y., Payton, O. D., RussellPavier F. S., Fardoulis, J. S., Richards D. A., and Scott, T. B.: 3D unmanned aerial vehicle radiation mapping for assessing contaminant distribution and mobility, Int. J. Appl. Earth Obs., 52, 12-19, 2016.

Martinez-de, Dios, J. R., Merino, L., Caballero, F., and Ollero, A.: Automatic forest-fire measuring using ground stations and unmanned aerial systems, Sensors, 11, 6328-6353, 2011.

McGonigle, A. J. S., Aiuppa, A., Giudice, G., Tamburello, G., Hodson, A. J., and Gurrieri, S.: Unmanned aerial vehicle measure- ments of volcanic carbon dioxide fluxes, Geophys. Res. Lett., 35, 3-6, https://doi.org/10.1029/2007GL032508, 2008.

McKenzie, D., Shankar, U., Keane, R. E., Stavros, E. N., Heilman, W. E., Fox, D. G., and Riebau, A. C.: Smoke consequences of new wildfire regimes driven by climate change, Earth's Future, 2, 35-59, 2014.

Merino, L., Caballero, F., Martínez-de-Dios, J. R., Iván, M., and Aníbal, O.: An unmanned aircraft system for automatic forest fire monitoring and measurement, J. Intell. Robot. Syst., 65, 533548, 2012.

Middlemiss, R. P., Samarelli, A., Paul, D. J., Hough, J., Rowan, S., and Hammond, G. D.: The First Measurement of the Earth Tides with a MEMS Gravimeter, Nature, 531, 614-617, https://doi.org/10.1038/nature17397, 2016.

Molina, P., Colomina, I., Vitoria, T., Silva, P. F., Skaloud, J., Kornus, W., Prades, R., and Aguilera, C.: Searching lost people with UAVs: the system and results of the close-search project, International Archives of the Photogrammetry, Remote Sensing and Spatial Information Sciences, 39, 441-446, 2012.

Mori, T., Hashimoto, T., Terada, A., Yoshimoto, M., Kazahaya, R., Shinohara, H., and Tanaka, R.: Volcanic plume measurements using a UAV for the $2014 \mathrm{Mt}$. Ontake eruption, Earth, Planets Sp., 68, 49, https://doi.org/10.1186/s40623-016-0418-0, 2016.

Murphy, R. R., Steimle, E., Griffin, C., Cullins, C., Hall, M., and Pratt, K.: Cooperative use of unmanned sea surface and micro aerial vehicles at Hurricane Wilma, J. Field Robot., 25, 164-180, 2008.

Nagatani, K., Akiyama, K., Yamauchi, G., Otsuka, H., Nakamura, T., Kiribayashi, S., Yoshida, K., Hada, Y., Yuta, S., Fujino, K., Izu, T., and Mackay, R.: Volcanic ash observation in active volcano areas using teleoperated mobile robots - Introduction to our robotic-volcano-observation project and field experiments, in: Proc. 2013 IEEE International Symposium on Safety, Security, and Rescue Robotics (SSRR), Linkoping, Sweden, 21-26 October 2013, 1-6, 2013.

Nakamura, F., Shimatani, Y., Nishihiro, J., Ohtsuki, K., Itsukushima, R., and Yamada, H.: Report on flood disaster in Kinu River, occurred in September, 2015, Ecol. Civ. Eng., 19, 259267, https://doi.org/10.3825/ece.19.259, 2017 (in Japanese with English abstract).

Nakano, T., Kamiya, I., Tobita, M., Iwahashi, J., and Nakajima, H.: Landform monitoring in active volcano by UAV and SFM-MVS technique, Int. Arch. Photogramm. Remote Sens. Spat. Inf. Sci. - ISPRS Arch., 40, 71-75, 2014.

Nedjati, A., Vizvari, B., and Izbirak, G.: Post-earthquake response by small UAV helicopters, Nat. Hazards, 80, 1669-1688, https://doi.org/10.1007/s11069-015-2046-6, 2016.

Nex, F. and Remondino, F.: UAV for 3D mapping applications: a review, Appl. Geomatics, 6, 1-15, https://doi.org/10.1007/s12518 013-0120-x, 2014.

Nex, F., Rupnik, E., Toschi, I., and Remondino, F.: Automated processing of high resolution airborne images for earthquake damage assessment, Int. Arch. Photogramm. Remote Sens. Spatial Inf. Sci., XL-1, 315-321, https://doi.org/10.5194/isprsarchivesXL-1-315-2014, 2014.

Nex, F., Gerke, M., Remondino, F., Przybilla, H.-J., Bäumker, M., and Zurhorst, A.: ISPRS Benchmark for Multi-Platform Photogrammetry, ISPRS Annals of the Photogrammetry, Remote 
Sensing and Spatial Information Sciences, II3/W4, 135-142, 2015.

Niculiţă, M.: Automatic landslide length and width estimation based on the geometric processing of the bounding box and the geomorphometric analysis of DEMs, Nat. Hazards Earth Syst. Sci., 16, 2021-2030, https://doi.org/10.5194/nhess-162021-2016, 2016.

Niethammer, U., Rothmund, S., and Joswig, M.: UAV-based remote sensing of the slow-moving landslide Super-Sauze, in: Proceedings of the International Conference on Landslide Processes: from geomorpholgic mapping to dynamic modelling, edited by: Malet, J.-P., Remaître, A., and Boogard, T., Strasbourg, CERG Editions, 69-74, 2009.

Niethammer, U., Rothmund, S., James, M. R., Travelletti, J., and Joswig, M.: UAV-based remote sensing of landslides. In Proceedings of the International Archives of Photogrammetry, Remote Sensing and Spatial Information Sciences, Commission V Symposium, Newcastle upon Tyne, UK, 21-24 June 2010, 496-501, 2010.

Niethammer, U., Rothmund, S., Schwaderer, U., Zeman, J., and Joswig, M.: Open Source Image-Processing Tools for Low-Cost UAV-Based Landslide Investigations. International Archives of the Photogrammetry, Remote Sensing and Spatial Information Sciences, Volume XXXVIII-1/C22, 2011 ISPRS Zurich 2011 Workshop, 14-16 September 2011, Zurich, Switzerland, 161166, 2011.

Niethammer, U., James, M. R., Rothmund, S., Travelletti, J., and Joswig, M.: UAV-based remote sensing of the Super-Sauze landslide: evaluation and results, Eng. Geol., 128, 2-11, 2012.

Nishar, A., Richards, S., Breen, D., Robertson, J., and Breen, B.: Thermal infrared imaging of geothermal environments and by an unmanned aerial vehicle (UAV): A case study of the Wairakei Tauhara geothermal field, Taupo, New Zealand, Renew. Energ., 86, 1256-1264, https://doi.org/10.1016/j.renene.2015.09.042, 2016.

Nocerino, E., Menna, F., Remondino, F., and Saleri, R: Accuracy and block deformation analysis in automatic UAV and terrestrial photogrammetry - Lesson learnt. ISPRS Annals of the Photogrammetry, Remote Sensing and Spatial Information Sciences, Vol. II(5/W1), Proc. 24th Intern. CIPA Symposium, 2-6 Sept., Strasbourg, France, 203-208, 2013.

Obanawa, H., Hayakawa, Y., and Gomez, C.: 3D Modelling of inaccessible Areas using UAV-based Aerial Photography and Structure from Motion, Transactions of the Japanese Geomorphological Union, 35, 283-294, 2014.

Peppa, M. V., Mills, J. P., Moore, P., Miller, P. E., and Chambers, J. E.: Brief communication: Landslide motion from cross correlation of UAV-derived morphological attributes, Nat. Hazards Earth Syst. Sci., 17, 2143-2150, https://doi.org/10.5194/nhess17-2143-2017, 2017.

Peters, M. P., Iverson, L. R., Matthews, S. N., and Prasad, A. M.: Wildfire hazard mapping: exploring site conditions in eastern US wildland-urban interfaces, Int. J. Wildland Fire, 22, 567-578, 2013.

Pham, T.-T.-H., Apparicio, P., Gomez, C., Weber, C., and Mathon, D.: Towards a rapid automatic detection of building damage using remote sensing for disaster management. The Haiti earthquake, Dis. Prev. Manage., 23, 53-66, https://doi.org/10.1108/DPM-12-2012-0148, 2014.
Piras, M., Taddia, G., Forno, M. G., Gattiglio, M., Aicardi, I., Dabove, P., Lo Russo, S., and Lingua, A.: Detailed geological mapping in mountain areas using an unmanned aerial vehicle: application to the Rodoretto Valley, NW Italian Alps, Geomatics, Natural Hazards and Risk, 8, 137-149, 2017.

Pollefeys, M., Gool, L. V., Vergauwen, M., Cornelis, K., Verbiest, F., and Tops, J.: Image-Based 3D Acquisition of Archaeological Heritage and Applications, Proc. Conf. on Virtual Reality, Archeology, and Cultural Heritage, 255-262, 2001.

Pratt, K. S., Murphy, R., Stover, S., and Griffin, C.: Conops and autonomy recommendations for VTOL small unmanned aerial system based on Hurricane Katrina operations, J. Field Robot., 26, 636-650, 2009.

Pyo, J., Cho, H., Joe, H., Ura, T., and Yu, S.: Development of hovering type AUV "Cyclops" and its performance evaluation using image mosaicing, Ocean Eng., 109, 517-530, https://doi.org/10.1016/j.oceaneng.2015.09.023, 2015.

Rau, J. Y., Jhan, J. P., Lo, C. F., and Lin, Y. S.: Landslide mapping using imagery acquired by a fixed-wing UAV, International Archives of the Photogrammetry, Remote Sensing and Spatial Information Sciences, Volume XXXVIII-1/C22, 2011 ISPRS Zurich 2011 Workshop, 14-16 September 2011, Zurich, Switzerland, 195-200, 2011.

Razak, K. A., Santangelo, M., Van Westen, C. J., Straatsma, M. W., and de Jong, S. M.: Generating an optimal DTM from airborne laser scanning data for landslide mapping in a tropical forest environment, Geomorphology, 190, 112-125, https://doi.org/10.1016/j.geomorph.2013.02.021, 2013.

Rossi, G., Tanteri, L., Tofani, V., Vannocci, P., Moretti, S., and Casagli, N.: Brief Communication: Use of multicopter drone optical images for landslide mapping and characterization, Nat. Hazards Earth Syst. Sci. Discuss., https://doi.org/10.5194/nhess2017-46, 2017.

Ryan, J. C., Hubbard, A. L., Box, J. E., Todd, J., Christoffersen, P., Carr, J. R., Holt, T. O., and Snooke, N.: UAV photogrammetry and structure from motion to assess calving dynamics at Store Glacier, a large outlet draining the Greenland ice sheet, The Cryosphere, 9, 1-11, https://doi.org/10.5194/tc-9-1-2015, 2015.

Saiki, K. and Ohba, T.: Development of an unmanned observation aerial vehicle (UAV) as a tool for volcano survey (in Japanese with English abstract), Bull. Volcanol. Soc. Japan Second Ser., 55, 137-146, 2010.

Salvini, R., Mastrorocco, G., Seddaiu, M., Rossi, D., and Vanneschi, C.: The use of an unmanned aerial vehicle for fracture mapping within a marble quarry (Carrara, Italy): photogrammetry and discrete fracture network modelling, Geomatics, Natural Hazards and Risk, 8, 34-52, 2017.

Salvini, R., Mastrorocco, G., Esposito, G., Di Bartolo, S., Coggan, J., and Vanneschi, C.: Use of a remotely piloted aircraft system for hazard assessment in a rocky mining area (Lucca, Italy), Nat. Hazards Earth Syst. Sci., 18, 287-302, https://doi.org/10.5194/nhess-18-287-2018, 2018.

Sanada, Y. and Torii T.: Aerial radiation monitoring around the Fukushima Dai-ichi nuclear power plant using an unmanned helicopter, J. Environ. Radioactiv., 139, 294-299, 2015.

Santangelo, M., Cardinali, M., Rossi, M., Mondini, A. C., and Guzzetti, F.: Remote landslide mapping using a laser rangefinder binocular and GPS, Nat. Hazards Earth Syst. Sci., 10, 2539 2546, https://doi.org/10.5194/nhess-10-2539-2010, 2010. 
Saroglou, C., Asteriou, P., Zekkos, D., Tsiambaos, G., Clark, M., and Manousakis, J.: UAV-based mapping, back analysis and trajectory modeling of a coseismic rockfall in Lefkada island, Greece, Nat. Hazards Earth Syst. Sci., 18, 321-333, https://doi.org/10.5194/nhess-18-321-2018, 2018.

Scaioni, M., Longoni, L., Melillo, V., and Papini, M.: Remote Sensing for Landslide Investigations: An Overview of Recent Achievements and Perspectives, Remote Sens., 6, 9600-9652, 2014 ,

Schroeder, W., Oliva, P., Giglio, L., Quayle, B., Lorenz, E., and Morelli, F.: Active fire detection using Landsat-8/OLI data, Remote Sens. Environ., 185, 210-220, 2016.

Şerban, G., Rus, I., Vele, D., Breţcan, P., Alexe, M., and Petrea, D.: Flood-prone area delimitation using UAV technology, in the areas hard-to-reach for classic aircrafts: case study in the north-east of Apuseni Mountains, Transylvania, Nat. Hazards, 82, 18171832, https://doi.org/10.1007/s11069-016-2266-4, 2016.

Shinohara, H.: Composition of volcanic gases emitted during repeating Vulcanian eruption stage of Shinmoedake, Kirishima volcano, Japan, Earth Planets Sp., 65, 667-675, https://doi.org/10.5047/eps.2012.11.001, 2013.

Smith, M. W., Carrivick, J. L., Hooke, J., and Kirkby, M. J.: Reconstructing flash flood magnitudes using "Structure-fromMotion": A rapid assessment tool, J. Hydrol., 519, 1914-1927, https://doi.org/10.1016/j.jhydrol.2014.09.078, 2014.

Sohn, H., Heo, J., Yoo, H., Kim, S., and Cho, H.: Hierarchical multisensor approach for the assessment of flood related damages, Proc. XXI Congr., 207-210, 2008.

Stöcker, C., Bennett, R., Nex, F., Gerke, M., and Zevenbergen, J.: Review of the current state of UAV regulations, Remote Sens., 9, 459, https://doi.org/10.3390/rs9050459, 2017.

Tang, L. and Shao, G.: Drone remote sensing for forestry research and practices, J. Forest Res., 26, 791-797, 2015.

Tamminga, A. D., Eaton, B. C., and Hugenholtz, C. H.: UASbased remote sensing of fluvial change following an extreme flood event, Earth Surf. Proc. Land., 40, 1464-1476, https://doi.org/10.1002/esp.3728, 2015.

Tannant, D. D., Giordan, D., and Morgenroth, J.: Characterization and analysis of a translational rockslide on a stepped-planar slip surface, Eng. Geol., 220, 144-151, 2017.

Tarolli, P.: High-resolution topography for understanding Earth surface processes: opportunities and challenges, Geomorphology, 216, 295-312, 2014.

Thamm, H. P. and Judex, M.: The "Low cost drone" - An interesting tool for process monitoring in a high spatial and temporal resolution. The International Archives of Photogrammetry, Remote Sensing and Spatial Information Sciences, Enschede, the Netherlands, Vol. XXXVI part 7, 2006.

Tobita, M., Kamiya, I., Iwahashi, J., Nakano, T., and Takakuwa, N.: UAV aerial photogrammetry in Nishinoshima Island and its analysis, Bull. Geospatial Inf. Auth. Japan, 125, 115-124, 2014a (in Japanese).

Tobita, M., Kamiya, I., Nakano, T., Iwahashi, J., Osumi, K., and Takakuwa, N.: Precise UAV aerial photogrammetry in Nishinoshima Island, Bull. Geospatial Inf. Auth. Japan, 125, 145-154, 2014b (in Japanese).

Tokarczyk, P., Leitao, J. P., Rieckermann, J., Schindler, K., and Blumensaat, F.: High-quality observation of surface imperviousness for urban runoff modelling using UAV imagery, Hydrol. Earth
Syst. Sci., 19, 4215-4228, https://doi.org/10.5194/hess-19-42152015, 2015.

Torrero, L. Seoli, L. Molino, A. Giordan, D. Manconi, A. Allasia, P., and Baldo, M.: The Use of Micro-UAV to Monitor Active Landslide Scenarios, in: Engineering Geology for Society and Territory, edited by: Lollino, G., Manconi, A., Guzzetti, F., Culshaw, M., Bobrowsky P., and Luino, F., Springer International Publishing, Switzerland, 5, 701-704, https://doi.org/10.1007/978-3-31909048-1_136, 2015.

Török, Á., Barsi, Á., Bögöly, G., Lovas, T., Somogyi, Á., and Görög, P.: Slope stability and rockfall assessment of volcanic tuffs using RPAS with 2-D FEM slope modelling, Nat. Hazards Earth Syst. Sci., 18, 583-597, https://doi.org/10.5194/nhess-18583-2018, 2018.

Travelletti, J., Delacourt, C., Allemand, P., Malet, J. P., Schmittbuhl, J., Toussaint, R., and Bastard, M.: Correlation of multi-temporal ground-based optical images for landslide monitoring: application, potential and limitations, ISPRS J. Photogramm. Remote Sens., 70, 39-55, 2012.

Tu, J., Sui, H., Feng, W., Sun, K., Xu, C., and Han, Q.: Detecting building facade damage from oblique aerial images using local symmetry feature and the Gini Index, Remote Sens. Lett., 8, 676685, 2017.

Turner, D. and Lucieer, A.: Using a micro unmanned aerial vehicle (UAV) for ultra-high resolution mapping and monitoring of landslide dynamics, in: Proceedings of the IEEE International Geoscience and Remote Sensing Symposium, Melbourne, Australia, 25 July 2013.

Turner, D., Lucieer, A., and Watson, C.: An automated technique for generating georectified mosaics from ultrahigh resolution unmanned aerial vehicle (UAV) imagery, structure from motion (SfM) point clouds, Remote Sens., 4, 1392-1410, 2012.

Turner, D., Lucieer, A., and de Jong, S. M.: Time Series Analysis of Landslide Dynamics Using an Unmanned Aerial Vehicle (UAV), Remote Sens., 7, 1736-1757, 2015.

UVS international: https://uvs-international.org, last access: 3 March 2018.

Van Den Eeckhaut, M., Poesen, J., Verstraeten, G., Vanacker, V., Nyssen, J., Moeyersons, J., van Beek, L. P. H., and Vandekerckhove, L.: Use of LIDAR-derived images for mapping old landslides under forest, Earth Surf. Proc. Land., 32, 754-769, https://doi.org/10.1002/esp.1417, 2007.

Van Westen, J. C., Castellanos, E., and Kuriakose, S. L.: Spatial data for landslide susceptibility, hazard, and vulnerability assessment: An overview, Eng. Geol., 102, 112-131, 2008.

Vetrivel, A., Gerke, M., Kerle, N., and Vosselman, G.: Identification of damage in buildings based on gaps in 3D point clouds from very high resolution oblique airborne images, ISPRS Journal of Photogrammetry and Remote Sensing, 105, 61-78, 2015.

Vetrivel, A., Gerke, M., Kerle, N., Nex, F., and Vosselman, G.: Disaster damage detection through synergistic use of deep learning and $3 \mathrm{D}$ point cloud features derived from very high resolution oblique aerial images, and multiple-kernel-learning, ISPRS Journal of Photogrammetry and Remote Sensing, https://doi.org/10.1016/j.isprsjprs.2017.03.001, in press, 2017.

Walter, M., Niethammer, U., Rothmund, S., and Joswig, M.: Joint analysis of the Super-Sauze (French Alps) mudslide by nanoseismic monitoring and UAV-based remote sensing, EAGE First Break, 27, 75-82, 2009. 
Wen, Q., He, H., Wang, X., Wu, W., Wang, L., Xu, F., Wang, P., Tang, T., and Lei, Y.: UAV remote sensing hazard assessment in Zhouqu debris flow disaster, in: Remote Sensing of the Ocean, Sea Ice, Coastal Waters, and Large Water Regions, edited by: Bostater, C. R., Ertikas, S. P., Neyt, X., and Velez-Reyes, M., 8 pp., 2011.

Westoby, M. J., Brasington, J., Glasser, N. F., Hambrey, M. J., and Reynolds, M. J.: Structure-from-Motion photogrammetry: A low-cost, effective tool for geoscience applications, Geomorphology, 179, 300-314, 2012.

Wing, M. G., Burnett, J. D., and Sessions, J.: Remote sensing and unmanned aerial system technology for monitoring and quantifying forest fire impacts, Int. J. Remote. Sens. Appl., 4, 18-35, 2014.

Witek, M., Jeziorska, J., and Niedzielski, T.: An experimental approach to verifying prognoses of floods using an unmanned aerial vehicle, Meteorol. Hydrol. Water Manag., 2, 3-11, 2014.

Woodget, A. S., Carbonneau, P. E., Visser, F., and Maddock, I. P.: Quantifying submerged fluvial topography using hyperspatial resolution UAS imagery and structure from motion photogrammetry, Earth Surf. Proc. Land., 40, 47-64, https://doi.org/10.1002/esp.3613, 2015.
Xie, Z., Yang, J., Peng, C., Wu, Y., Jiang, X., Li, R., Zheng, Y., Gao, Y., Liu, S., and Tian, B.: Development of an UAS for post-earthquake disaster surveying and its application in Ms7.0 Lushan Earthquake, Sichuan, China, Comput. Geosci., 68, 22 30, 2014.

Yajima, R., Nagatani, K., and Yoshida, K.: Development and field testing of UAV-based sampling devices for obtaining volcanic products, in 2014 IEEE International Symposium on Safety, Security, and Rescue Robotics, 27-30 October 2014, Hokkaido, Japan, 1-5, 2014.

Yoon, W. S., Jeong, U. J., and Kim, J. H.: Kinematic analysis for sliding failure of multi-faced rock slopes, Eng. Geol., 67, 51-61, 2002.

Zajkowski, T. J., Dickinson, M. B., Hiers, J. K., Holley, W., Williams, B. W., Paxton, A., Martinez, O., and Walker, G. W.: Evaluation and use of remotely piloted aircraft systems for operations and research - RxCADRE 2012, Int. J. Wildland Fire, 25, 114-128, 2015.

Zazo, S., Molina, J. L., and Rodríguez-Gonzálvez, P.: Analysis of flood modeling through innovative geomatic methods, J. Hydrol., 524, 522-537, https://doi.org/10.1016/j.jhydrol.2015.03.011, 2015. 